\title{
Promoting Oxygen Electrochemical Reduction to Hydrogen Peroxide through Fabricating Hierarchical Pores
}

\author{
Shaojie Wang ${ }^{1}$, Jiping Luo ${ }^{1}$, Lele Yuan ${ }^{1}$, Mengyao Chen ${ }^{1}$, Wei Ma ${ }^{1}$, Peiqin Sun ${ }^{1}$, and \\ Shaohui Sun $^{1}$ \\ ${ }^{1}$ Affiliation not available
}

April 28, 2020

\begin{abstract}
In this work, we demonstrate an effective approach to enhance the activity and selectivity of carbon materials for hydrogen peroxide (H2O2)production by means of interface engineering. Carbon black and/or graphite are mixed with polytetrafluoroethylene(PTFE)and pore-forming agent to form a gas diffusion electrode for $\mathrm{H} 2 \mathrm{O} 2$. Structural characterizations find that PTFE not only acts as a binder, it also changes the original pore size distribution of carbon materials by increasing the number of mesoporous and micron pores. These unique hierarchical pores enhance an efficient gas transmission and dispersion network system. Meanwhile, a number of polymer phases are generated in the inner of electrode with the size of $30 \mathrm{~nm}-1 \mu \mathrm{m}$, which enhance the affinity of catalyst surface to oxygen. Under the detachable H-type $\mathrm{H} 2 \mathrm{O} 2$ test device and optimized conditions, $\mathrm{H} 2 \mathrm{O} 2$ concentration can reach $11.8 \mathrm{wt} \%$. The simple physical mixing engineering fabricating hierarchical pores would be helpful to other electrochemical processes involving gas-solid-liquid three-phase interface.
\end{abstract}

Promoting Oxygen Electrochemical Reduction to Hydrogen Peroxide through Fabricating Hierarchical Pores

Shaojie Wang, Jiping Luo, Lele Yuan, Mengyao Chen, Wei Ma, Peiqin Sun, Shaohui Sun*.

*Engineering Research Center of Advanced Functional Material Manufacturing of Ministry of Education, Zhengzhou University, Zhengzhou 450001, China.

[Abstract] In this work, we demonstrate an effective approach to enhance the activity and selectivity of carbon materials for hydrogen peroxide $\left(\mathrm{H}_{2} \mathrm{O}_{2}\right)$ production by means of interface engineering. Carbon black and/or graphite are mixed with polytetrafluoroethylene(PTFE)and pore-forming agent to form a gas diffusion electrode for $\mathrm{H}_{2} \mathrm{O}_{2}$. Structural characterizations find that PTFE not only acts as a binder, it also changes the original pore size distribution of carbon materials by increasing the number of mesoporous and micron pores. These unique hierarchical pores enhance an efficient gas transmission and dispersion network system. Meanwhile, a number of polymer phases are generated in the inner of electrode with the size of $30 \mathrm{~nm}-1 \mu \mathrm{m}$, which enhance the affinity of catalyst surface to oxygen. Under the detachable H-type $\mathrm{H}_{2} \mathrm{O}_{2}$ test device and optimized conditions, $\mathrm{H}_{2} \mathrm{O}_{2}$ concentration can reach $11.8 \mathrm{wt} \%$. The simple physical mixing engineering fabricating hierarchical pores would be helpful to other electrochemical processes involving gas-solid-liquid three-phase interface.

Key Words :interface engineering, hierarchical pores, gas diffusion electrode, $2 \mathrm{e}^{-}$-ORR, $\mathrm{H}_{2} \mathrm{O}_{2}$ 


\section{Introduction}

Hydrogen peroxide $\left(\mathrm{H}_{2} \mathrm{O}_{2}\right)$, one of the 100 most important chemical substances, is a versatile and environmentally friendly oxidizer ${ }^{[1]}$, which is widely used in chemical synthesis ${ }^{[2]}$, water treatment ${ }^{[3]-[6]}$ and environmental treatment ${ }^{[7]-[8]}$. At present, the main industrial production method of $\mathrm{H}_{2} \mathrm{O}_{2}$ is anthraquinone method ${ }^{[9]-[12]}$. However, the direct catalytic method of hydrogen and oxygen ${ }^{[13]-[14]}$ and the electrocatalytic method ${ }^{[15]-[27]}$ to produce $\mathrm{H}_{2} \mathrm{O}_{2}$ have the advantages of green and environmental protection, and are feasible alternative methods for industrial production. It is safer to produce $\mathrm{H}_{2} \mathrm{O}_{2}$ by $2 \mathrm{e}-\mathrm{ORR}$ on the surface of gas diffusion electrode (GDE). Hydrogen peroxide prepared in the field can be directly used for disinfection and sewage treatment.

The reaction mechanism of oxygen reduction under acidic conditions mainly involves two electrons and four electrons:

$\mathrm{O} 2+2 \mathrm{e}^{-}+2 \mathrm{H}^{+}-\mathrm{H} 2 \mathrm{O} 2(0.695 \mathrm{~V} v$. SHE) (1)

$\mathrm{H} 2 \mathrm{O} 2+2 \mathrm{e}^{-}+2 \mathrm{H}^{+}-2 \mathrm{H} 2 \mathrm{O}(1.760 \mathrm{~V} v$ s. SHE) $(2)$

$\mathrm{O} 2+4 \mathrm{e}^{-}+4 \mathrm{H}^{+}-2 \mathrm{H} 2 \mathrm{O}(1.229 \mathrm{Vvs}$. SHE) (3)

High $\mathrm{H}_{2} \mathrm{O}_{2}$ selectivity and current efficiency can be obtained by increasing the rate of reaction (1) and inhibiting the occurrence of reactions (2) and (3). Previous studies have found that platinum-based materials are excellent ORR catalysts ${ }^{[28]-[29]}$, while the relatively cheap carbon oxide materials have a significant advantage in 2e-ORR activity ${ }^{[30]-[35]}$. For most carbon-based materials (such as carbon nanotubes $(\mathrm{CNTs}){ }^{[36]-[39]}$, carbon black ${ }^{[40]-[42]}$, acetylene black ${ }^{[43]-[44]}$, graphene ${ }^{[45]-[48]}$ and carbon fiber ${ }^{[49]}$, the 2e-overpotential of $\mathrm{O}_{2}$ conversion to $\mathrm{H}_{2} \mathrm{O}_{2}$ is low, and the modification and regulation of carbon materials are convenient. By the introduction of nonmetal impurity atoms (such as $\mathrm{O}^{[50]-[52]}, \mathrm{N}^{[53]-[57]}, \mathrm{F}^{[58]-[59]}, \mathrm{P}^{[60]}, \mathrm{B}^{[61]}$, $\mathrm{S}^{[62]-[64]}$, etc.) or the introduction of metal oxides ${ }^{[65]-[68]}$ of the doping modification methods for carbon materials, we can change the physical structure or electron configuration, and reach the purpose of increasing its intrinsic activity, and obtain high efficiency, high selectivity, high stability of the 2e--ORR catalysts.

At present, the means to improve the catalytic performance of carbon materials are mainly focus on the regulation of defects and active sites, but there are few reports on optimizing the interface design of carbon-based catalysts to improve gas transport and fabricate more three-phase interfaces. In the process of electrocatalysis, especially under the condition of high current density, fabricating a developed hierarchical pores network is conducive to diffusion and mass transfer. $\mathrm{O}_{2}$ diffuses to the surface of the catalytic active site through the pores, and reacts with the $\mathrm{H}^{+}$in the electrolyte and the electrons in the catalytic layer at the gas-solid-liquid three-phase interface, promoting the improvement of $\mathrm{H}_{2} \mathrm{O}_{2}$ reaction rate.

In this paper, cheap conductive carbon black (Vulcan XC-72R) and graphite are used as electrode materials, by adding PTFE - pore-making agent and simple processing, then a gas diffusion electrode with diffusion layer and catalytic layer is prepared. Under the optimized ratio and processing conditions, the electrode not only has rough surface and multi-stage micro-nano scale composite structure, but also the polymer phase regulates the wetting property of interface gas and liquid. The obtained concentration of hydrogen peroxide at $11.7 \mathrm{wt} \%$ is superior to most reported materials. Based on the theory of Bulter-Volmer polarization curve, we also set up a mass transfer model for the three-phase interface reaction under the real reaction condition, and simulate the variation law of concentration polarization and current density in the three-phase region. This study demonstrates the great potential of PTFE in the construction of high-performance three-phase interfaces using simple porous materials and provides new ideas for the design of key catalytic materials and functional interfaces in other areas of electrochemical catalysis. 


\section{Experimental}

\subsection{Preparation of gas diffusion electrode}

(1) Pretreatment of stainless steel mesh:

Firstly, the stainless steel mesh (40 mesh, Runshi metal products factory) is cut into length $\times$ width $=5 \mathrm{~cm} \times 5 \mathrm{~cm}$ specification, and soaked in $5 \%$ of the mass of PTFE emulsion (PTFE) for $5-10 \mathrm{~s}$. Then we take it out and put it in a oven at 105 to dry. Repeating the above operation several times, until the weight of stainless steel mesh is doubled, and dry for $1 \mathrm{~h}$.

(2) Preparation of carbon black, pore-forming agent and binder paste:

According to the dry weight ratio, we weigh the carbon materials(Vulcan XC-72R, AR, Cabot, USA; Graphite powder, AR, Tianjin chemical reagent factory), binder (60wt \% of PTFE, Japan Daikin company) and poreforming agent $\left(\mathrm{NH}_{4} \mathrm{HCO}_{3}, \mathrm{AR}\right.$, Tianjin wind ship chemical technology co., LTD.). Then, we mix them evenly, and add an appropriate amount of ethanol (AR, characters). Ultrasonic shocks for 20min and disperses them evenly, and volatilizes the ethanol at 40 to a thick paste, which is carbon black, pore-forming agent and binder paste.

The typical formula is carbon material and PTFE mass ratio of 2:1, at this case, electrode abbreviation is $\mathrm{Gr} / \mathrm{PTFE} 0.5$ or CB/PTFE0.5, Gr: CB: PTFE= 1:1:1, electrode abbreviation is Gr0.5CB0.5 /PTFE0.5. Where: Gr and CB are graphite powder and carbon black (Vulcan XC-72R) powder.

(3) Preparation and molding of gas diffusion electrode

The paste is evenly coated on the hydrophobic stainless steel mesh and pressed at $6 \mathrm{MPa}$ pressure for 20min to obtain the initial gas diffusion electrode. The initial gas diffusion electrode is placed in a muffle furnace and calcined at 330 for $1 \mathrm{~h}$. After cooling, the electrode is taken out and soaked in deionized water for $2 \mathrm{~h}$.

\subsection{Characterization and analytical methods}

(1) Nitrogen adsorption and desorption test (BET)

The pore size distribution and specific surface area of electrode materials are measured by ASAP2460 gas adsorption analyzer.

(2) Raman spectral representation

Conducted in the SENTERRA Raman Scope (BRUKER) tester, the excitation source wavelength is 532nm and the power is about $2 \mathrm{~mW}$.

(3) Fourier-transform infrared spectroscopy (FTIR)

The vibration absorption characteristics of chemical bonds or functional groups in molecules are used to test the molecular structure and functional groups of electrode materials by FTIR.

(4) Scanning electron microscopy (SEM)

SEM is used to observe the structure, material distribution and microscopic pore distribution of the electrode surface.

(5) Electrochemical Tests

The performance of selective oxygen reduction is assessed in a standard three-electrode system controlled by a potentiostat (CHI 760E) with a RDE setup. A glassy carbon (GC) disc (RRDE-3A; Pine Instrument Company; $0.0707 \mathrm{~cm}^{2}$ of disc area) is employed as the working electrode. The Pt wire and saturated $\mathrm{Ag} / \mathrm{AgCl}$ electrode are used as the counter and reference electrode, respectively. All the reported potentials are referred to as the reversible hydrogen electrode (RHE) potential. 
The catalyst ink is prepared by dispersing $15 \mathrm{mg}$ of carbon materials catalyst in $800 \mu \mathrm{L}$ of isopropyl alcohol, $800 \mu \mathrm{L}$ of deionized water and $14 \mu \mathrm{L}$ of $5 \mathrm{wt} \%$ Nafion solution, followed by a sonication of $30 \mathrm{~min}$. After that, $9.6 \mu \mathrm{L}$ of the catalyst ink is deposited on the GC part of the RDE electrode and dried to form a uniform thin film at 95 keeping 12h. An $\mathrm{O}_{2}$-saturated $0.5 \mathrm{M} \mathrm{Na}_{2} \mathrm{SO}_{4}(\mathrm{pH}=1.0)$ aqueous solution is used as an electrolyte for measurement. The working electrode is rotating at $1600 \mathrm{rpm}$.

Linear sweep voltammetry (LSV) is carried out to compare the electrochemical behavior during $\mathrm{H}_{2} \mathrm{O}_{2}$ production, and are performed by the electrochemical workstation at a scan rate of $5 \mathrm{mV}^{*} \mathrm{~s}^{-1}$ in the three-electrode cell system. The prepared cathode is used as working electrode. The Pt wire and saturated $\mathrm{Ag} / \mathrm{AgCl}$ electrode are used as the counter and reference electrode, respectively. All the reported potentials are referred to as the reversible hydrogen electrode (RHE) potential. The LSV curves of the working electrodes are obtained in the potential range of $0.0-0.9 \mathrm{~V}$ in $\mathrm{O}_{2}$-saturated $\mathrm{Na}_{2} \mathrm{SO}_{4}$ solution $(\mathrm{pH}=1.0)$, ambient temperature.

\subsection{Experimental methods and devices}

Gas diffusion electrode is assembled in the removable H-type experiment device, the typical conditions of the preparation of hydrogen peroxide are the cathode chamber volume $7 \mathrm{~cm}^{3}$, the thickness of $1 \mathrm{~cm}$, anode platinum electrode, Proton Exchange Membrane (PEM), electrolyte, $0.5 \mathrm{~mol}^{*} \mathrm{~L}^{-1} \mathrm{Na}_{2} \mathrm{SO}_{4}$ solution ( $\mathrm{pH}=1.0$ ), current $1.05 \mathrm{~A}, \mathrm{O}_{2}$ flow rate $30 \mathrm{ml}^{*} \mathrm{~min}^{-1}$, circulating pump flow $20 \mathrm{ml}^{*} \mathrm{~min}^{-1}$, reaction, every $10 \mathrm{~min}$ sampling, the determination of $\mathrm{H}_{2} \mathrm{O}_{2}$ concentration.

\subsection{Analysis and calculation methods}

(1) Determination of $\mathrm{H}_{2} \mathrm{O}_{2}$ concentration

The concentration of $\mathrm{H}_{2} \mathrm{O}_{2}$ is determined by colorimetry, using $0.1 \mathrm{~mol} * \mathrm{~L}^{-1} \mathrm{Ti}\left(\mathrm{SO}_{4}\right)_{2}$ as chromogenic agent. The ultraviolet spectrophotometer detects that its maximum absorption wavelength is at $407 \mathrm{~nm}$. Diluted with $30 \mathrm{wt} \% \mathrm{H}_{2} \mathrm{O}_{2}$ into a series of concentration gradients of $1-60 \mathrm{mg}^{*} \mathrm{~L}^{-1}$, under $407 \mathrm{~nm}$ absorption wavelength, the standard curve of absorbance (A) and $\mathrm{H}_{2} \mathrm{O}_{2}$ concentration (C) is made, which meets the following requirements: $\mathrm{A}=0.023 \mathrm{C}$. concentration of experimental sample can be calculated according to the standard curve of absorbance- $\mathrm{H}_{2} \mathrm{O}_{2}$ concentration.

(2)The current efficiency of the $\mathrm{H}_{2} \mathrm{O}_{2}$ electrosynthesis was calculated using Eq. (1)

$F E=\frac{\mathrm{nFCV}}{\mathrm{It}} \times 100 \%(1)$

Where $n$ is the number of transferred electrons in the reduction of $\mathrm{O}_{2}$ to $\mathrm{H}_{2} \mathrm{O}_{2}(\mathrm{n}=2), F$ is the Faraday constant $\left(96485 \mathrm{C}^{*} \mathrm{~mol}^{-1}\right), C$ is the concentration of $\mathrm{H}_{2} \mathrm{O}_{2}\left(\mathrm{~mol}^{*} \mathrm{~L}^{-1}\right), V$ is the volume of electrolyte $(\mathrm{L}), I$ is the current intensity (A), and $t$ is the electrocatalysis time (s).

(3) Calculation of $\mathrm{H}_{2} \mathrm{O}_{2}$ generation rate

The apparent generation rate of $\mathrm{H}_{2} \mathrm{O}_{2}$ is the difference between the net generation rate of $\mathrm{H}_{2} \mathrm{O}_{2}$ and the decomposition rate. We usually use the net generation rate of $\mathrm{H}_{2} \mathrm{O}_{2}$ to describe the electrochemical activity of the electrode. According to the relationship between the concentration of $\mathrm{H}_{2} \mathrm{O}_{2}(C)$ and the reaction time $(t)$, the apparent formation rate of $\mathrm{H}_{2} \mathrm{O}_{2}$ is $r=d C / d t$. After reasonable derivation and calculation, the influence of $\mathrm{H}_{2} \mathrm{O}_{2}$ decomposition is eliminated, and when $\mathrm{r}$ is extrapolated to $t=0 \mathrm{~min}$, the net generation rate of $\mathrm{H}_{2} \mathrm{O}_{2}\left(r_{t=0}\right)$ is obtained to reflect the electrochemical activity of the electrode. 


\section{Results and discussion}

3.1 Pores characterization of GDE materials
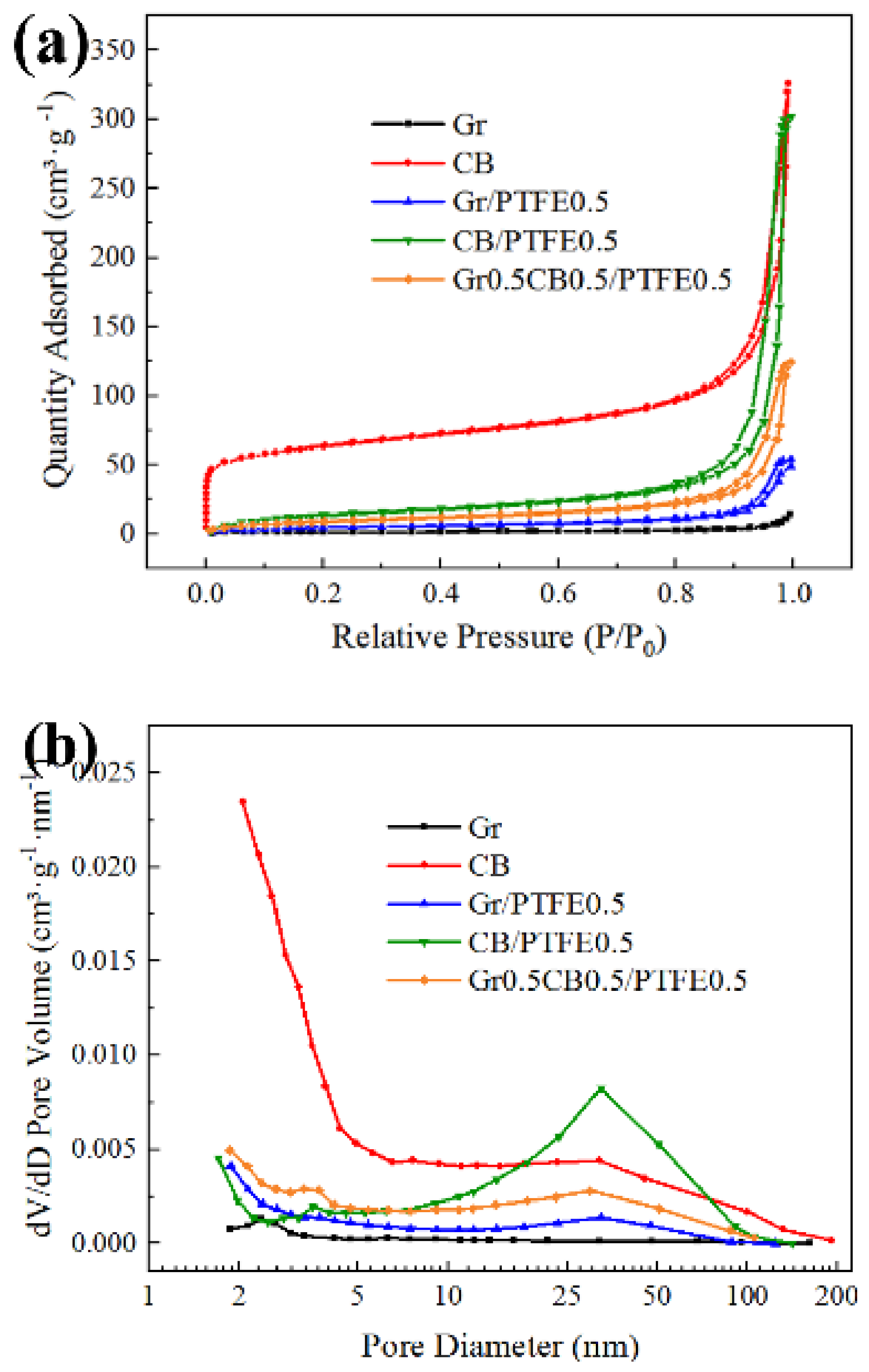

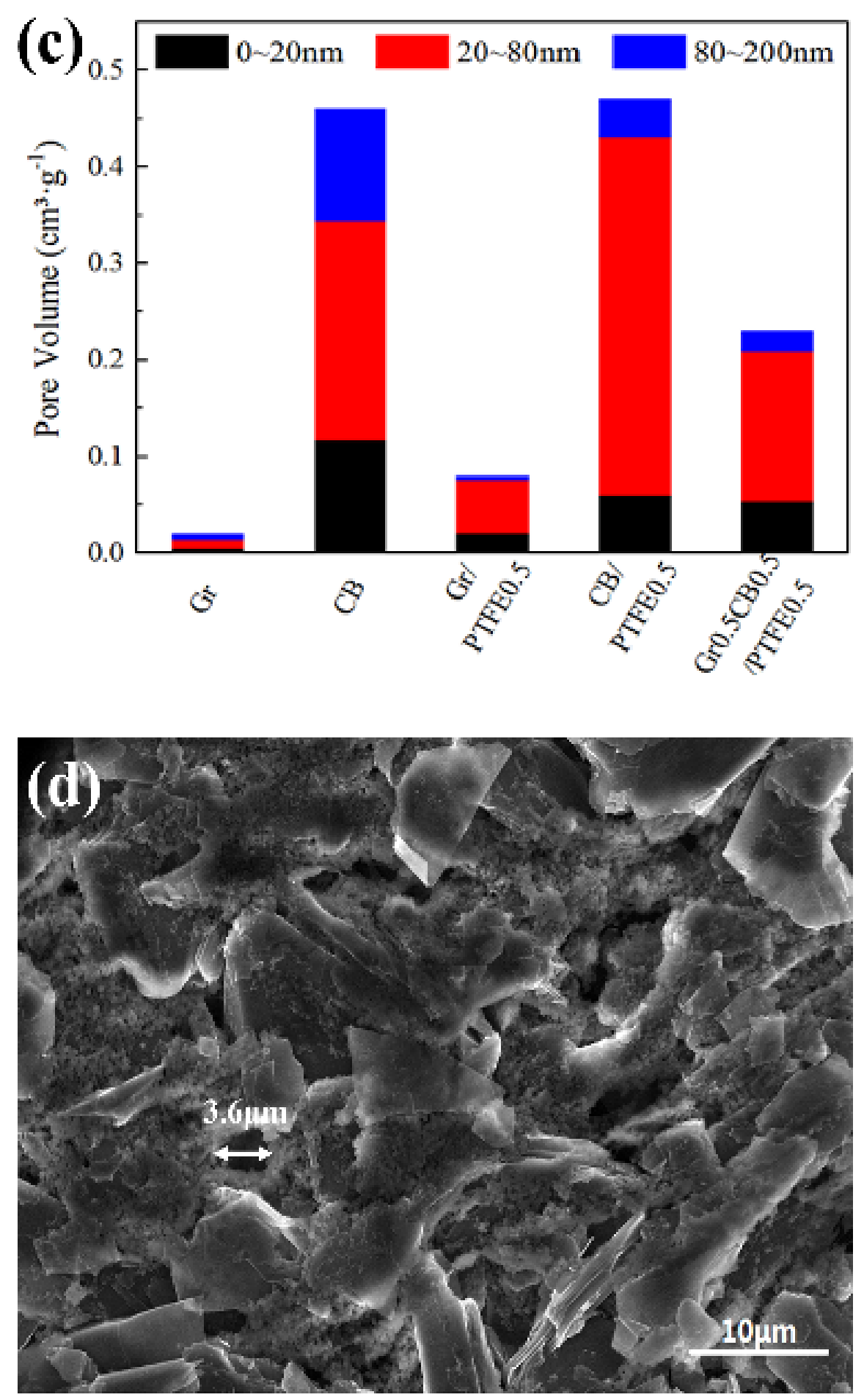

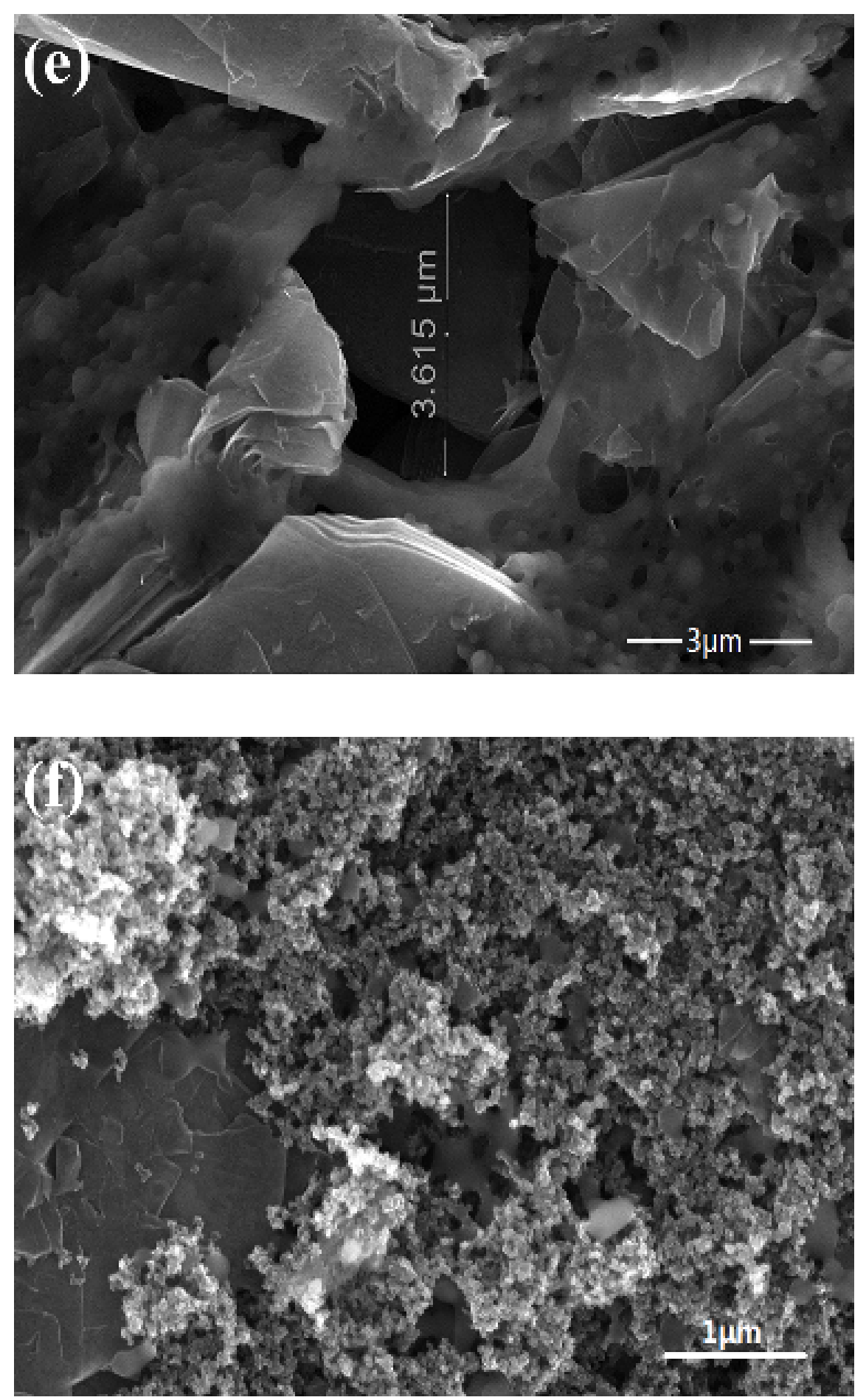

Fig.1 Characterization results of physical property parameters of electrode material. (a)-(c) are the characterization results of BET :(a) $\mathrm{N}_{2}$ isothermal adsorption and desorption curves of electrode materials composed of different formulations;(b) pore volume distribution of electrode materials composed of different formulations;(c) pore volume distribution of electrode materials composed of different formulations.(d)-(f) is the SEM image of the electrode material with the formed composition of Gr0.5CB0.5/PTFE0.5. 
In order to determine the pore structures and specific surface area of electrode materials with the range of $0-200 \mathrm{~nm}, \mathrm{~N}_{2}$ adsorption measurements are performed. The $\mathrm{N}_{2}$ isothermal adsorption and desorption curves of different carbon-based catalytic materials determined by BET are shown in Fig.1a, and specific specific surface area and pore volume data are shown in Table.S1. Fig.1a shows that the geometric morphologies of graphite (Gr) and carbon black (CB) are greatly different. The pore structure is almost absent in graphite, the specific surface area is only $4.38 \mathrm{~m}^{2 *} \mathrm{~g}^{-1}$, and the pore volume is close to 0. After adding PTFE and pore-forming agent, the specific surface area increased to $18.67 \mathrm{~m}^{2} \mathrm{~g}^{-1}$ and the pore volume increased to $0.08 \mathrm{~cm}^{3 *} \mathrm{~g}^{-1}$, indicating the formation of some type of secondary pore structure.

From Fig.1a - Table.S1, it can be also found that the BET surface area of CB is $206 \mathrm{~m}^{2} \mathrm{~g}^{-1}$. The porous carbon sample exhibit a typical type I pattern for the $\mathrm{N}_{2}$ adsorption, which represents a sharp increase at low relative pressure $\left(\mathrm{P} / \mathrm{P}_{0}<0.1\right)$ due to the formation of microporous structure. Moreover, the $\mathrm{N}_{2}$ adsorptiondesorption isotherm curves for CB also show a typical type IV isotherm curve with an obvious hysteresis, implying the presence of mesoporous structure with a range of pore size from 20-80nm (Fig.1b). Furthermore, even as our BET results show that the specific surface area of CB/PTFE0.5 sample is obvious smaller than that of CB (Table.S1). But from (Fig.1b and 1c) we can see that the pore volume of per gram CB/PTFE0.5 sample is almost equal to that of $\mathrm{CB}$ owing to the formation of much more mesopores. If normalized to $1 \mathrm{~g}$ $\mathrm{CB}$ material, the CB0.5Gr0.5/PTFE0.5 sample also possess more mesopores volume than $\mathrm{CB}$ alone when PTFE and pore former are added to CB.

From Fig.1d-1f, we can know that after PTFE and pore-forming agent are properly added, the photo of surface morphology of different electrode materials under the scanning electron microscope. The brighter particles seen in Fig.1f are particles bonded together with carbon black, whose size is about 30-50nm. There are also some individual smooth dark gray polymer phases, ranging in size from 0.1 to $1 \mu \mathrm{m}$. Fig. $1 \mathrm{~d}$ shows the crystalline flake structure of the graphite, which is added to improve the mechanical strength of the electrode. In addition, many black pore structures $(0.5-5 \mu \mathrm{m})$ can be seen in Fig.1d to Fig.1g photos. These structures have different heights and heights in the field of electron microscopy, and even cause difficulty in photo focusing, which reflects that the surface roughness increases after emulsion and pore-forming agent are added. In summary, SEM images show that the carbon black, graphite and polymer phases not only form relatively uniform dispersion systems, but also form many micron-scale pore structures ranging from 0.5 to $5 \mu \mathrm{m}$.

In brief, based on the characterization results of BET and SEM, we believe that the addition of PTFE not only acts as a bonding molding agent, but also acts together with pore-forming agent. It changes the original pore size distribution of carbon materials, and increases the number of $20-80 \mathrm{~nm}$ pores. What's more, it forms a large number of micron pores, and combines with CB's unique nano-scale pore structure to form a nano-micron multi-stage pore structure. Later performance tests show that this unique hierarchical pore structures form an efficient gas transport and dispersion network system. Meanwhile, the dispersed polymer phase improves the affinity of the catalyst surface to oxygen, providing a suitable place for the rapid diffusion and migration of reactants and products. 
3.2 Surface defects and electrochemical active surface area
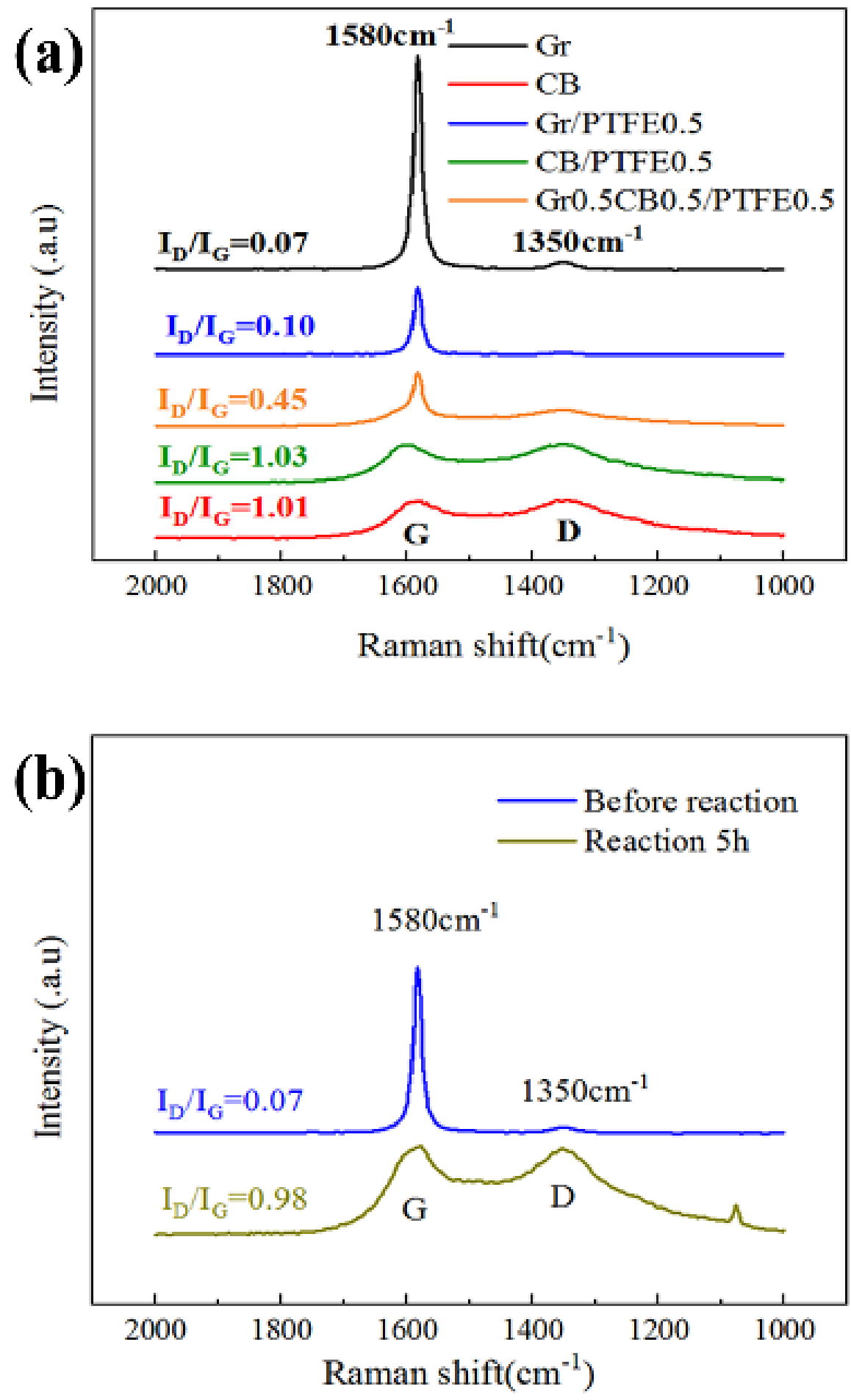

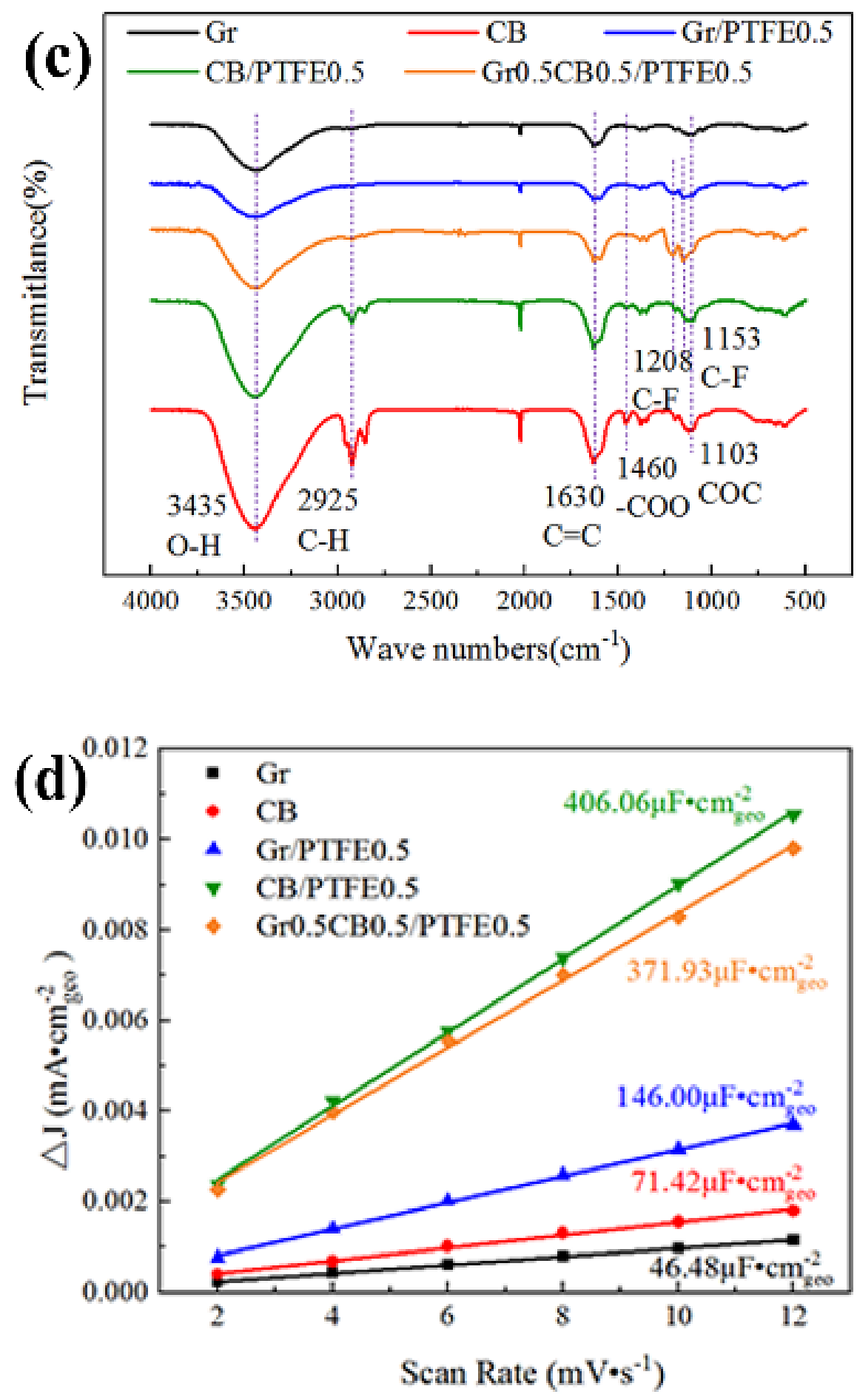

Fig.2 Characterization results of chemical property parameters of different electrode materials. (a) Raman diagram of different electrode materials at excitation source wavelength of $532 \mathrm{~nm}$; (b) Raman diagram of electrode $\mathrm{Gr}$ PTFE0.5 under the condition of $\mathrm{O}_{2}$ flow rate of $30 \mathrm{ml}^{*} \mathrm{~min}^{-1}$, current of $150 \mathrm{~mA}^{*} \mathrm{~cm}^{-2}, 0.5 \mathrm{~mol}^{*} \mathrm{~L}^{-1}$ $\mathrm{Na}_{2} \mathrm{SO}_{4}$ solution, $\mathrm{pH}=1.0$, before and after reaction for $5 \mathrm{~h}$; (c) Fourier infrared spectra of different electrode materials. The electrochemical test is carried out with $\mathrm{Ag} / \mathrm{AgCl}$ as the reference electrode, $\mathrm{Pt}$ electrode 
as the counter electrode, and rotating disk electrode (RDE) as the working electrode in $\mathrm{O}_{2}$ saturated 0.5 mol* ${ }^{-1} \mathrm{Na}_{2} \mathrm{SO}_{4}$ solution with $\mathrm{pH}=1.0$; (d) Double-layer capacitance test of different electrode materials at RDE speed of 1600rpm at different scanning rates.

Fig.2a shows the Raman spectrum of different electrode materials. Peak D $\left(1350 \mathrm{~cm}^{-1}\right)$ in the figure reflects the disordered structure of the material. Peak $G\left(1580 \mathrm{~cm}^{-1}\right)$ reflects the ordered structure of carbon materials. The larger the ratio of peak $\mathrm{D}$ to peak $\mathrm{G}$ strength, the more defect sites there are. From the Raman test results, it can be seen that the $\mathrm{I}_{\mathrm{D}} / \mathrm{I}_{\mathrm{G}}(0.07)$ of $\mathrm{Gr}$ is far less than that of $\mathrm{CB}$ (1.01), indicating that $\mathrm{CB}$ structure has a large degree of disorder and a large number of surface defect sites. Before and after the addition of PTFE, the $\mathrm{I}_{\mathrm{D}} / \mathrm{I}_{\mathrm{G}}$ of the material itself was almost unchanged, which indicated that no new defects are generated after the addition of PTFE, and the original crystal structure of Gr and CB materials is not changed. It can be seen from the Fig.2b graphite gas diffusion electrode after using $5 \mathrm{~h}, \mathrm{I}_{\mathrm{D}} / \mathrm{I}_{\mathrm{G}}$ value is similar to carbon materials, carbon black and disorder have no difference, showing that graphite crystal structure in the electrochemical oxygen enriched environment is destroyed by corrosion, and surface defects increase dramatically. In Fig. S2, a new absorption peak appeares in the IR spectrum of Gr/PTFE0.5 after reaction $5 \mathrm{~h}$ at $1451 \mathrm{~cm}^{-1}$, which also indicates that the surface of graphite material is oxidized to form carboxylic acid groups.

In order to investigate the changes in chemical composition of different electrode materials, the functional groups of the as-prepared samples are characterized by FT-IR(Fig2c). Fig.2c shows that the peak of $3435 \mathrm{~cm}^{-1}$ is the stretching vibration peak of $-\mathrm{OH}{ }^{[67]}$, and the absorption peak of $\sim 2925,1630$ and $1380 \mathrm{~cm}^{-1}$ respectively belongs to the stretching vibration of $\mathrm{C}-\mathrm{H}$ of $\mathrm{CB}^{[70]}, \mathrm{C}=\mathrm{C}^{[71]}$ and $\mathrm{C}-\mathrm{OH}$ group. In addition, $\mathrm{C}-$ O-C absorption $\left(\sim 1100 \mathrm{~cm}^{-1}\right)$ and -COO absorption $\left(\sim 1460 \mathrm{~cm}^{-1}\right)$ signal peaks appear in FT-IR spectrum ${ }^{[28]}$. Compared to $\mathrm{CB}$ and Gr in Fig. 2c, it can be seen that under the condition of the same determination of $\mathrm{CB}$ is better than the absorption of Gr signals, showing that $\mathrm{CB}$ surface more oxygen containing functional groups, and oxygen in the $\mathrm{CB}$ mainly $-\mathrm{OH}$, $-\mathrm{COC}$ - and $-\mathrm{O}-\mathrm{C}=\mathrm{O}$. According to report ${ }^{[43]}, \mathrm{O}_{2}$ adsorption on oxygen-containing functional groups (such as -COO-, -COC-) on the surface of $\mathrm{C}$ for the Pauling model. This Pauling model is conducive to the generation of ${ }^{*} \mathrm{OOH}$ intermediate during the 2e- oxygen reduction process, which is the active site for the generation of hydrogen peroxide. After PTFE is added, C-F vibration absorption peaks appear in the FT-IR spectrum in Fig.2c at $1220 \mathrm{~cm}^{-1}$ and $1153 \mathrm{~cm}^{-1}$, and the positions and intensity of the infrared absorption peaks of oxygen-containing functional groups don't change. It should be pointed out that these results are only static characterization. For reference, the study of Chuan Xia ${ }^{[72]}$ shows that surface modification of PTFE can improve oxygen adhesion, and the oxygen adsorbed near the active site during the reaction process will affect the adsorption and desorption intensity of the intermediate species in the electrochemical reaction, thus affecting the generation rate and selectivity of products.

In order to further explore the 2e-ORR performance of electrode materials, CHI760E electrochemical workstation is used to characterize the electrode materials through linear scanning voltammetry curve (LSV) and cyclic voltammetry curve (CV). The test results are listed in Table.1.

Table.1 Characterization results of different electrode materials

\begin{tabular}{llllll}
\hline & Onset Potential of ORR & Open circuit potential & $\mathrm{C}_{\mathrm{dl}}$ & ECSA & $\mathrm{S}_{\text {BET }}$ \\
\hline & (Vvs:RHE) & (V vs:RHE) & $\mu \mathrm{F}^{*} \mathrm{~cm}^{-2}$ geo & $\mathrm{m}^{2 *} \mathrm{~g}^{-1} \mathrm{cat}$ & $\mathrm{m}^{2 *} \mathrm{~g}^{-1}$ cat \\
$\mathrm{Gr}$ & -0.0171 & 0.147 & 46.5 & 0.176 & 4.38 \\
CB & 0.308 & 0.825 & 71.4 & 0.27 & 206 \\
Gr/PTFE0.5 & 0.0752 & 0.328 & 143 & 0.541 & 18.7 \\
CB/PTFE0.5 & 0.459 & 0.846 & 406 & 1.54 & 52.1 \\
Gr0.5CB0.5/PTFE0.5 & 0.193 & 0.786 & 372 & 1.41 & 34 \\
\hline
\end{tabular}

For ORR reaction, $\mathrm{CB}$ has a higher initial potential than Gr, indicating that $\mathrm{CB}$ has better catalytic activity than Gr. After the addition of PTFE, the initial potential of oxygen reduction increases and moves towards 
the direction of thermodynamic equilibrium potential, indicating that the catalytic activity of PTFE is improved. In Fig.S2e, the open circuit potential of $\mathrm{Gr}$ under the condition of saturated dissolved oxygen is $0.147 \mathrm{v}$, which is far less than that of CB $(0.825 \mathrm{v})$, indicating that the surface of Gr has less oxygen adsorption and basically no oxygen reduction catalytic activity, which is consistent with the previously characterized small specific surface area of $\mathrm{Gr}$ and fewer defects. For CB, due to the large specific surface area and more defects, the oxygen adsorbed on the surface of CB has a greater tendency to undergo reduction reaction, and $0.825 \mathrm{v}$ is higher than the standard potential of $0.69 \mathrm{v}$ of $2 \mathrm{e}$-reduction mechanism of oxygen, indicating the existence of 4e-reduction mechanism for CB.

After adding PTFE, the open circuit potential of Gr becomes $0.328 \mathrm{v}$, but it is still far away from the standard potential of $0.7 \mathrm{v}$, with poor activity. CB is compounded with $\mathrm{Gr}$ and added with PTFE (Gr0.5CB0.5/PTFE0.5), with an open-circuit potential of $0.786 \mathrm{~V}$, which is close to the oxygen 2e-reduction potential. Peer's study ${ }^{[7]}$ has also shown that the addition of PTFE can change the surface polarity of the material and increase the affinity adsorption capacity of oxygen. Whether the open circuit potential is closer to the standard potential and the selectivity of hydrogen peroxide generation is better still needs further experimental study.

In addition to increasing the activity of active sites, there are strategies to increase the number of active sites that affect the rate of hydrogen peroxide formation. By observing the variation trend of the capacitance reflecting the surface roughness of the electrode in Fig.S2d and the electrochemical active surface area in Table.1, we are surprised to find that the electrochemical active surface area with PTFE significantly increases, even though the electrochemical active surface area of PTFE with Gr is higher than that of the original CB material, indicating that the addition of PTFE significantly increases the number of active sites. This shows the important role of adding PTFE in promoting the formation of hydrogen peroxide. It can also be considered that the addition of PTFE resulted in the formation of hierarchical pore structure, and the presence of polymer phase also improved the affinity of catalyst surface to gas. More three-phase interfaces are constructed by the two kinds of interaction. This structure is conducive to oxygen transfer, oxygen adsorption and 2e-activation, thus improving the hydrogen peroxide generation rate and Faraday efficiency.

\subsection{The performance of synthesis $\mathrm{H}_{2} \mathrm{O}_{2}$ in a H-type cell}

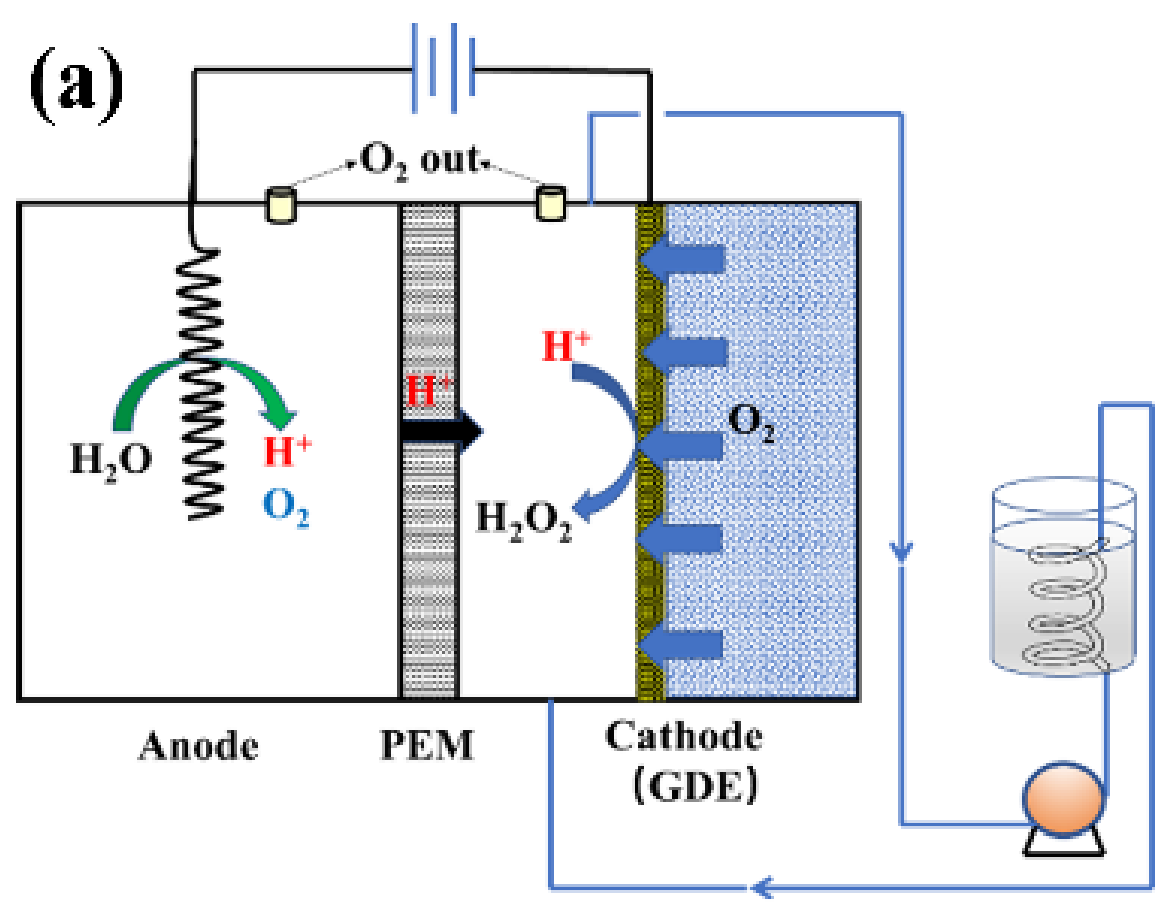



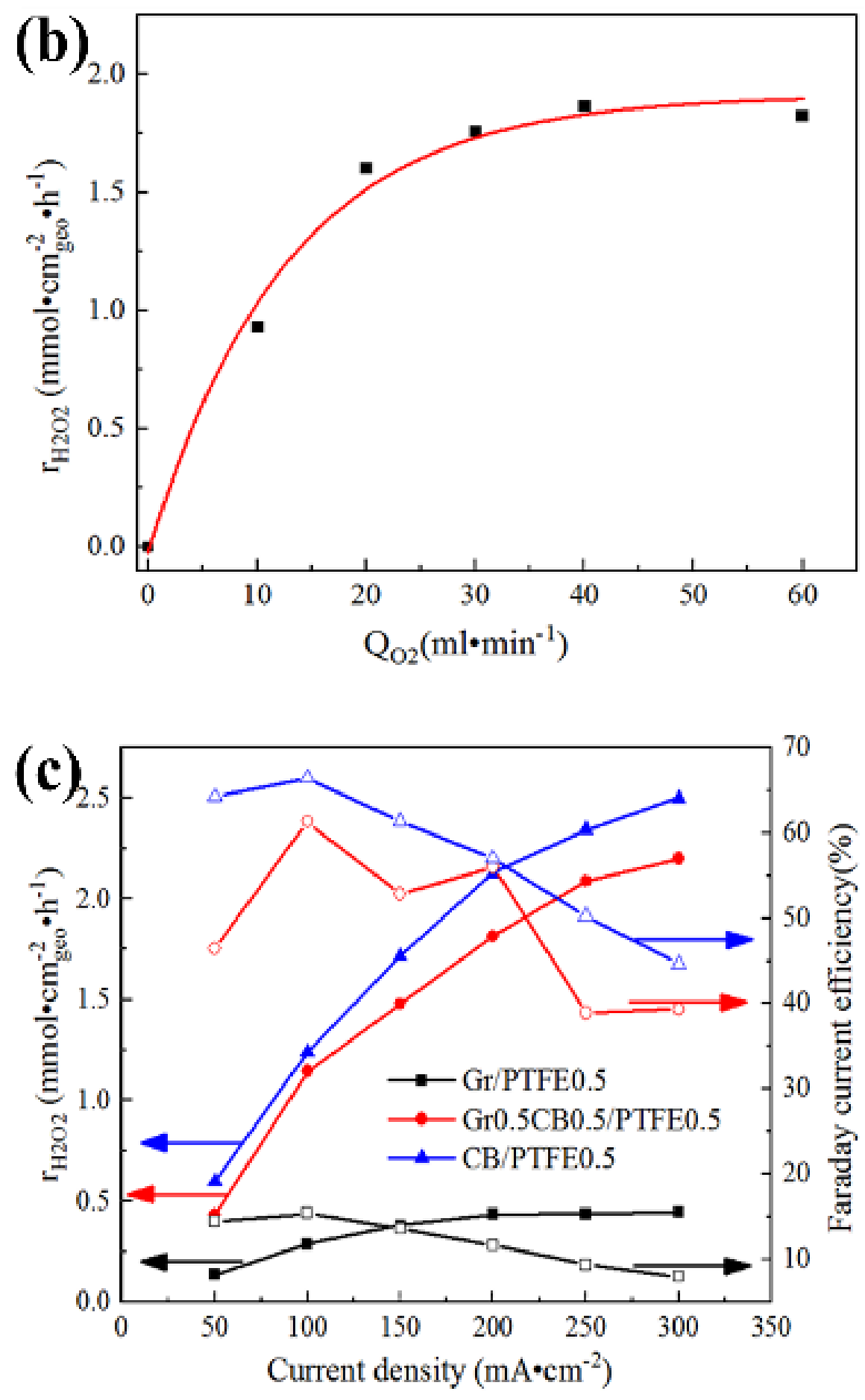

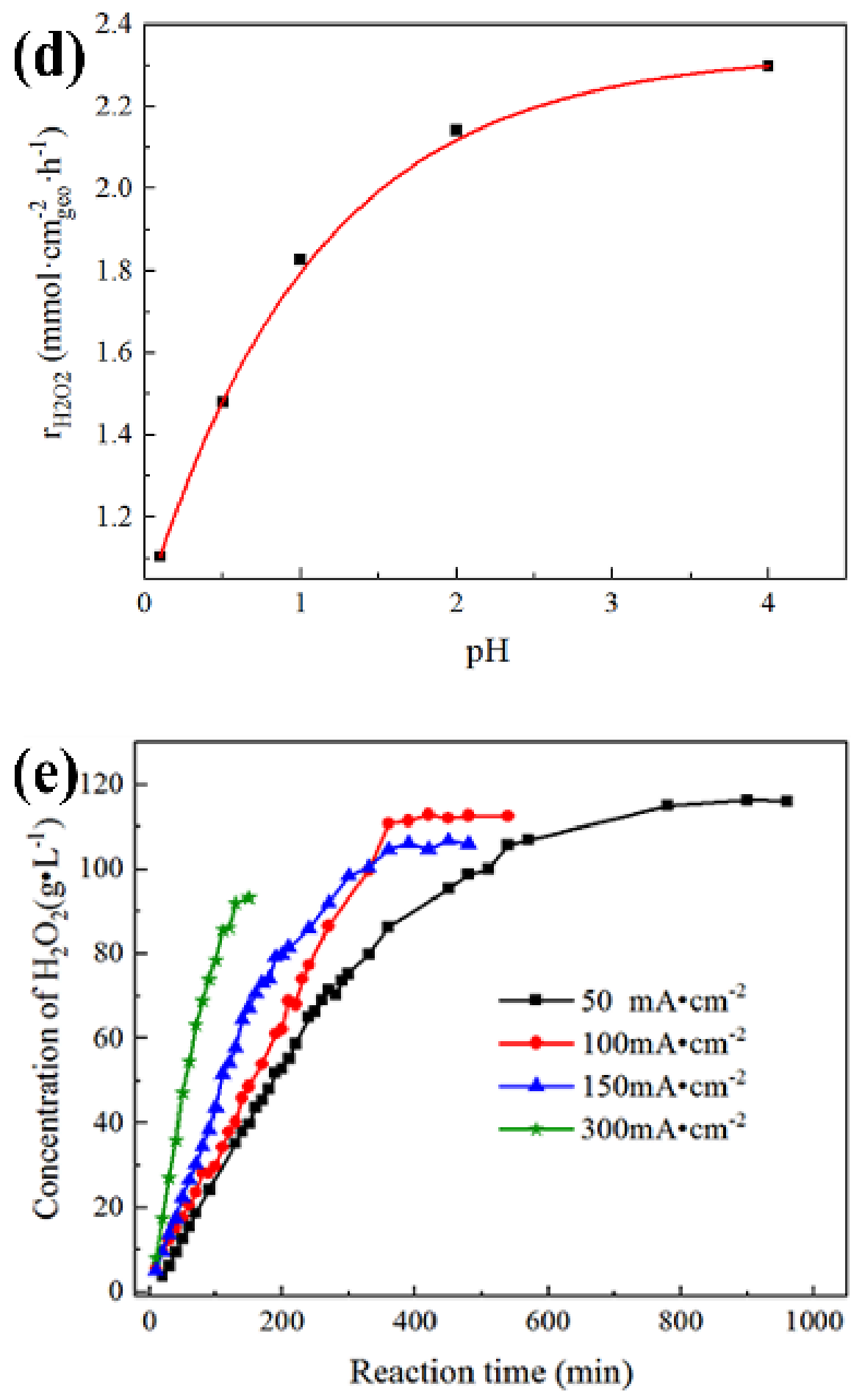


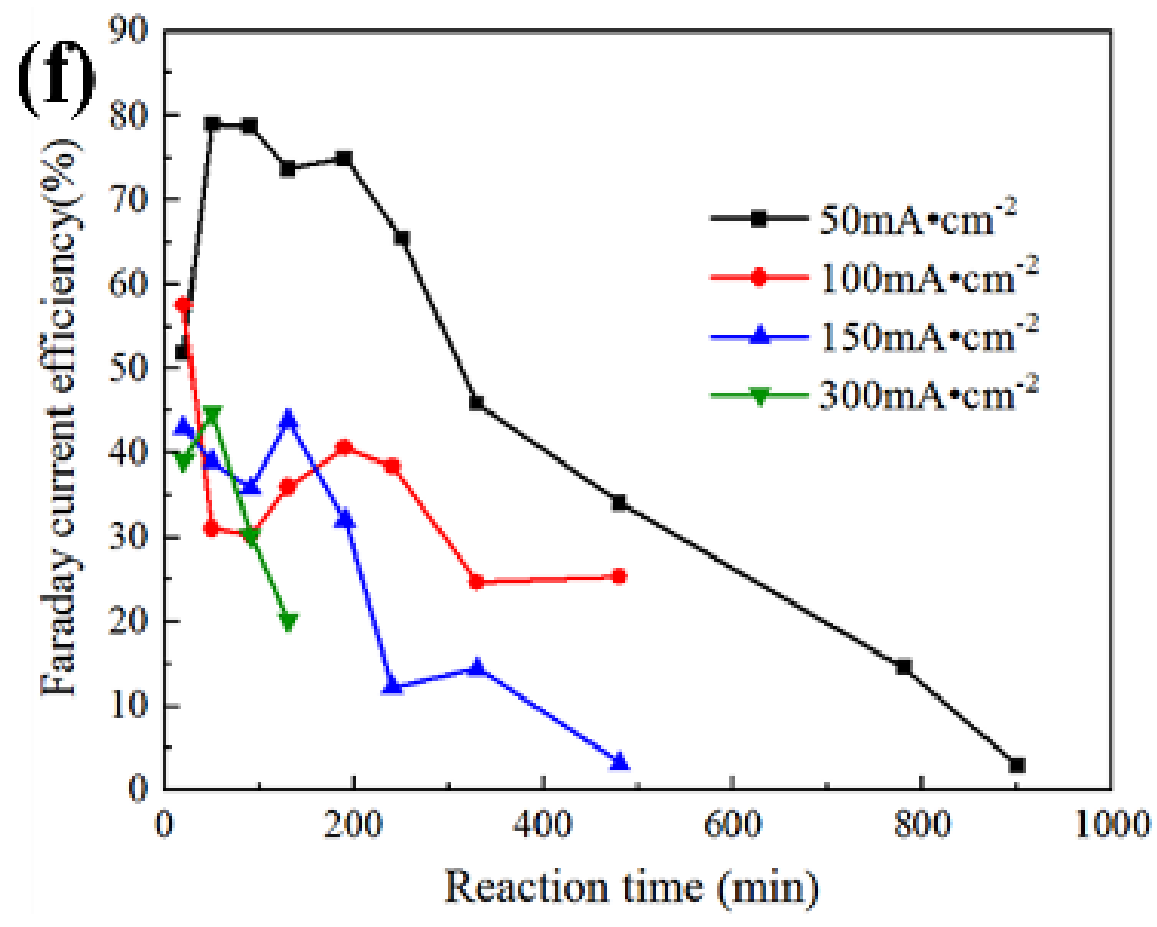

Fig.3 Device and performance test for generating $\mathrm{H}_{2} \mathrm{O}_{2}$.(a) Schematic diagram of h-type device generating $\mathrm{H}_{2} \mathrm{O}_{2}$, specification: length $\times$ width $\times$ height $=7 \mathrm{~cm} \times 5 \mathrm{~cm} \times 5 \mathrm{~cm}$, electrolytic liquid volume $20 \mathrm{ml}$; (b) At the electrode Gr0.5CB0.5/PTFE0.5, the net generation rate of $\mathrm{H}_{2} \mathrm{O}_{2}$ changes with the throughput of $\mathrm{O}_{2}$ under the conditions of current $150 \mathrm{~mA}^{*} \mathrm{~cm}^{-2}, 0.5 \mathrm{~mol}^{*} \mathrm{~L}^{-1} \mathrm{Na}_{2} \mathrm{SO}_{4}$ solution and $\mathrm{pH}=1.0$. (c)The net generation rate and Faraday current efficiency of $\mathrm{H}_{2} \mathrm{O}_{2}$ changed with the current density of electrodes with different compositions under the condition of $\mathrm{O}_{2}$ flow rate of $30 \mathrm{ml}^{*} \mathrm{~min}^{-1}, 0.5 \mathrm{~mol} * \mathrm{~L}^{-1} \mathrm{Na}_{2} \mathrm{SO}_{4}$ solution, $\mathrm{pH}=1.0$; (d) At the electrode Gr0.5CB0.5/PTFE0.5, the net generation rate of $\mathrm{H}_{2} \mathrm{O}_{2}$ varies with the $\mathrm{pH}$ of the electrolyte under the conditions of $\mathrm{O}_{2}$ flow rate of $30 \mathrm{ml}^{*} \mathrm{~min}^{-1}$, current $150 \mathrm{~mA}^{*} \mathrm{~cm}^{-2}$ and $0.5 \mathrm{~mol}^{*} \mathrm{~L}^{-1} \mathrm{Na}_{2} \mathrm{SO}_{4}$ solution; (e) Electrode Gr0.5CB0.5/PTFE0.5, under the condition of $\mathrm{O}_{2}$ flow rate of $30 \mathrm{ml}^{*} \mathrm{~min}^{-1}, 0.5 \mathrm{~mol} \mathrm{~L}^{-1} \mathrm{Na}_{2} \mathrm{SO}_{4}$ solution, $\mathrm{pH}=1.0$, the cumulative concentration of $\mathrm{H}_{2} \mathrm{O}_{2}$ changes with reaction time at different current density; (f) Electrode Gr0.5CB0.5/PTFE0.5 the Faraday current efficiency of generating $\mathrm{H}_{2} \mathrm{O}_{2}$ with different current density changes with reaction time under the condition of $\mathrm{O}_{2}$ flow rate of $30 \mathrm{ml}^{*} \mathrm{~min}^{-1}, 0.5 \mathrm{~mol}^{*} \mathrm{~L}^{-1}$ $\mathrm{Na}_{2} \mathrm{SO}_{4}$ solution, $\mathrm{pH}=1.0$.

Fig.3a shows the schematic diagram of the hydrogen peroxide generating unit. Oxygen passes through the gas diffusion electrode integrating the diffusion layer and the reaction layer, and the excess oxygen is discharged from the hydrogen peroxide solution in the cathode chamber. Fig.3b shows the relationship between the hydrogen peroxide generation rate and the oxygen flow rate at the current density of $150 \mathrm{~mA}^{*} \mathrm{~cm}^{-2}$. It can be seen that when the $\mathrm{O}_{2}$ flow rate is no less than $30 \mathrm{ml}^{*} \mathrm{~min}^{-1}$, the influence of $\mathrm{O}_{2}$ throughput on the generation of $\mathrm{H}_{2} \mathrm{O}_{2}$ can be excluded. Unless otherwise stated, the oxygen flow rate in the paper is $30 \mathrm{ml}^{*} \mathrm{~min}^{-1}$. The investigation results of some influencing factors such as the type of pore-making agent, partial pressure of oxygen, and addition ratio of carbon materials are shown in Fig.S3.

It can be seen from Fig.3c and Fig.S4c that no matter what kind of electrode, the hydrogen peroxide generation rate increases as the current density increases, but the increasing slope becomes smaller and smaller. After the current density exceeds $200 \mathrm{~mA}^{*} \mathrm{~cm}^{-2}$, it gradually becomes stable. The maximum hydrogen peroxide generation rate is about $2.5 \mathrm{mmol}^{*} \mathrm{~cm}^{-2 *} \mathrm{~h}^{-1}$, and the corresponding Faraday efficiency also decreases gradually. Comparing different electrodes, it can be found that the hydrogen peroxide generation rate in- 
creases with the increase of $\mathrm{CB}$ content. When the mass ratio of $\mathrm{CB} / \mathrm{Gr}[?] 1$, the electrode performance does not increase significantly. Compared with Gr0.5CB0.5/PTFE0.5 and CB/PTFE0.5, the pore volumes are significantly different, but the electrochemical active surface area is similar. We believe that the production rate of hydrogen peroxide depends on the electrochemical active surface area. Using carbon materials such as carbon black, which are much cheaper than graphene and carbon nanotubes, and simply adding PTEF, gas diffusion electrodes with high hydrogen peroxide rate can be obtained compared with other carbon materials.

As $\mathrm{pH}$ goes from 0 to 2 , the formation rate of $\mathrm{H}_{2} \mathrm{O}_{2}$ increases linearly, but when $\mathrm{pH}=2$ to 4 , the reaction rate is basically independent of $\mathrm{pH}$. With different $\mathrm{pH}$ range, the corresponding speed control steps of hydrogen peroxide generation may be different.

Fig.3e shows that with the increase of the current density, the generation rate of $\mathrm{H}_{2} \mathrm{O}_{2}$ increases, and the maximum cumulative concentration can be reached in a shorter time. At the current density of $50 \mathrm{~mA}^{*} \mathrm{~cm}^{-2}$ and $\mathrm{O}_{2}$ flow rate of $30 \mathrm{ml}^{*} \mathrm{~min}^{-1}$, after $780 \mathrm{~min}$, the maximum cumulative concentration of $\mathrm{H}_{2} \mathrm{O}_{2}$ reaches $117 \mathrm{~g}^{*} \mathrm{~L}^{-1}$, i.e. $3.44 \mathrm{~mol}^{*} \mathrm{~L}^{-1}$, or about $11.8 \%$ of the mass fraction. The maximum cumulative concentration is related to the decomposition of hydrogen peroxide. When the decomposition rate is increased to equal to the rate of hydrogen peroxide formation, the hydrogen peroxide concentration will remain constant for a long time if there is no mechanical damage to the electrode.

Fig.3f is the average Faraday efficiency of hydrogen peroxide concentration accumulated to a certain point. It can be seen that the electrodes are activated at the beginning. The Faraday current efficiency decreases rapidly with the increase of hydrogen peroxide concentration, reflecting that the decomposition of hydrogen peroxide into water will affect the overall electrode efficiency. When the hydrogen peroxide concentration is no longer rising, the instantaneous Faraday efficiency drops to zero. In addition, too high current density will reduce the service life of the electrode, and the surface of the electrode where the micro-pore structure is damaged has hydrogen generation, which will also reduce the Faraday efficiency of hydrogen peroxide generation. 
3.4 Simulating the polarization curve under real reaction conditions based on Bulter-Volmer equation

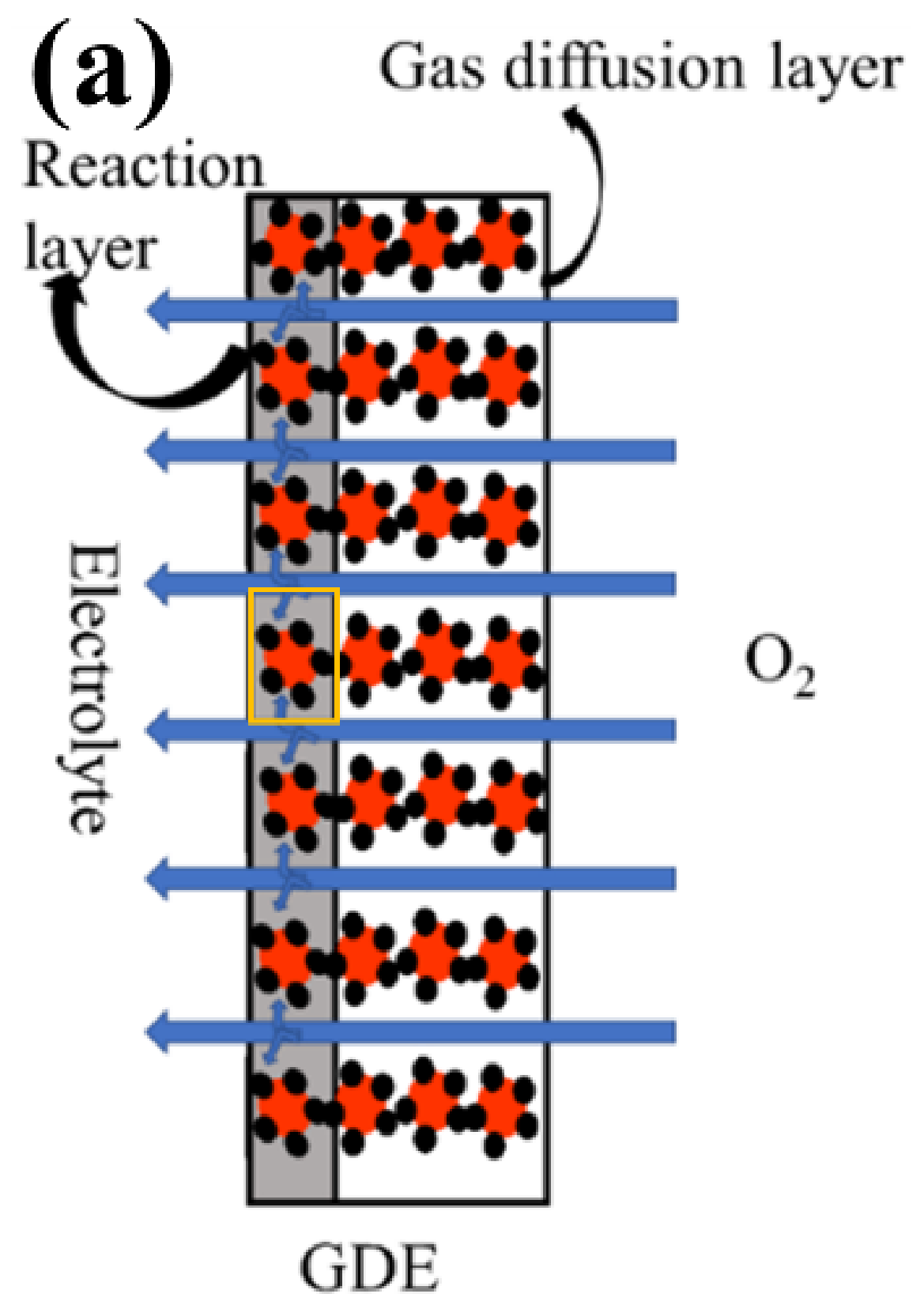




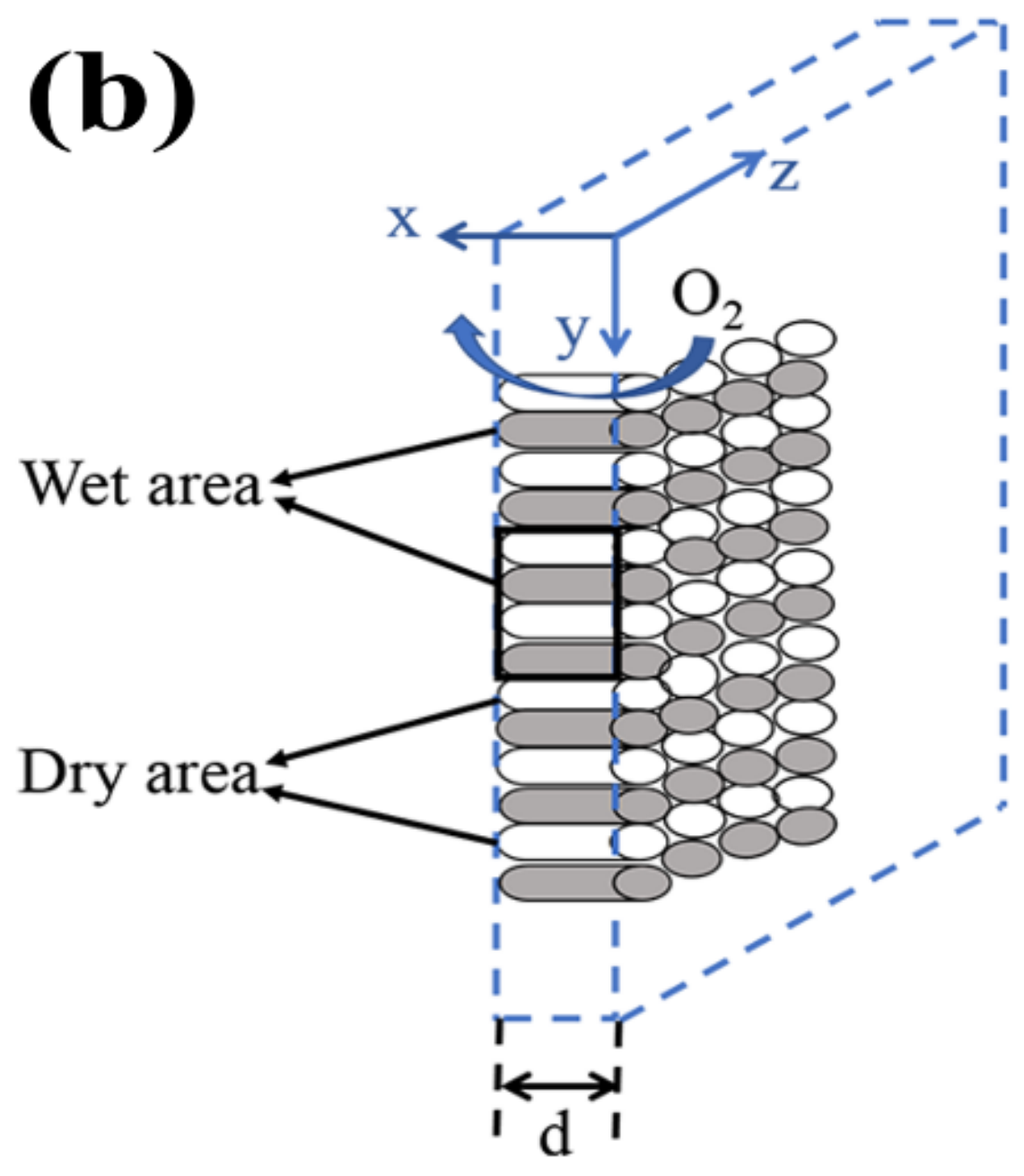




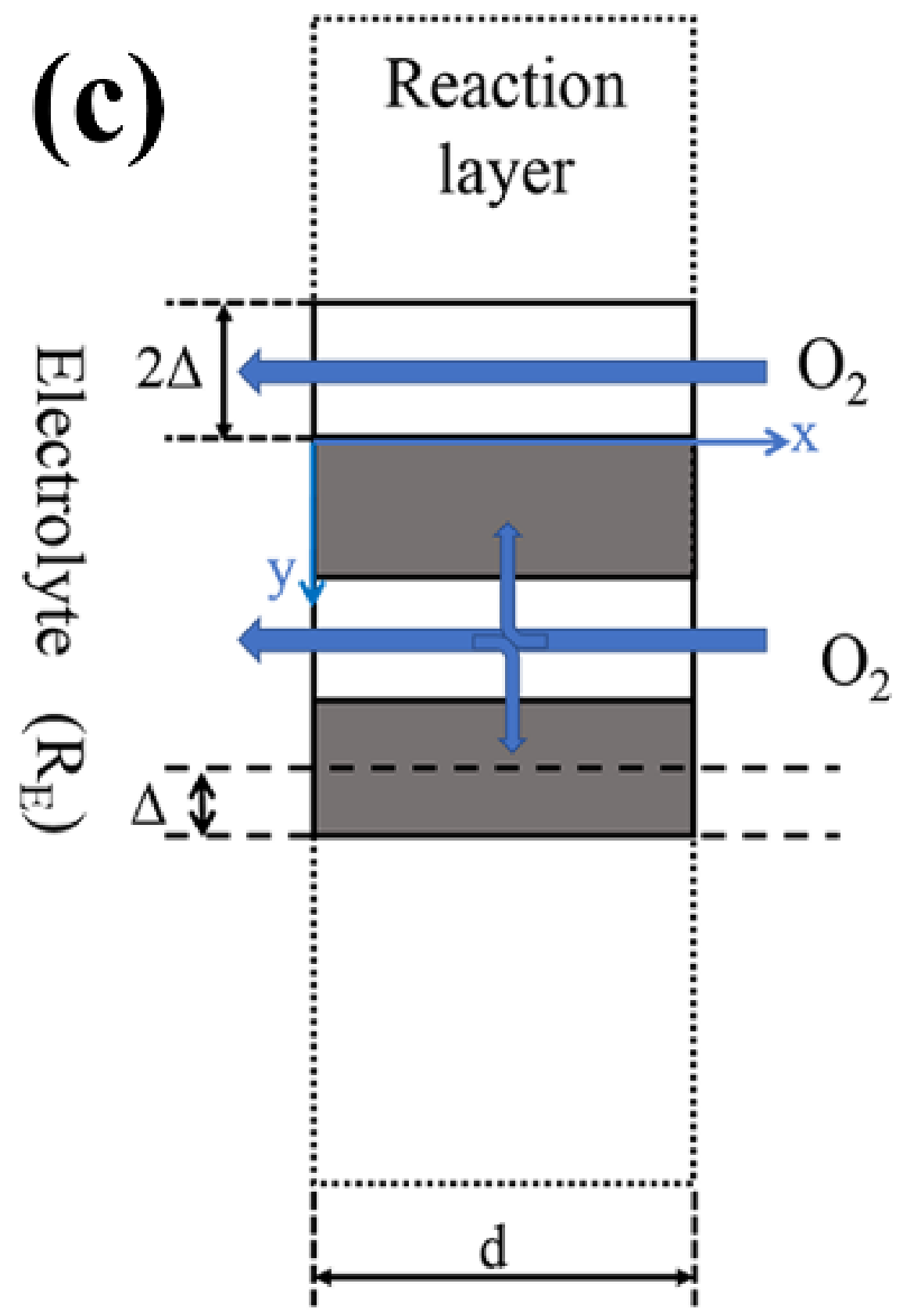



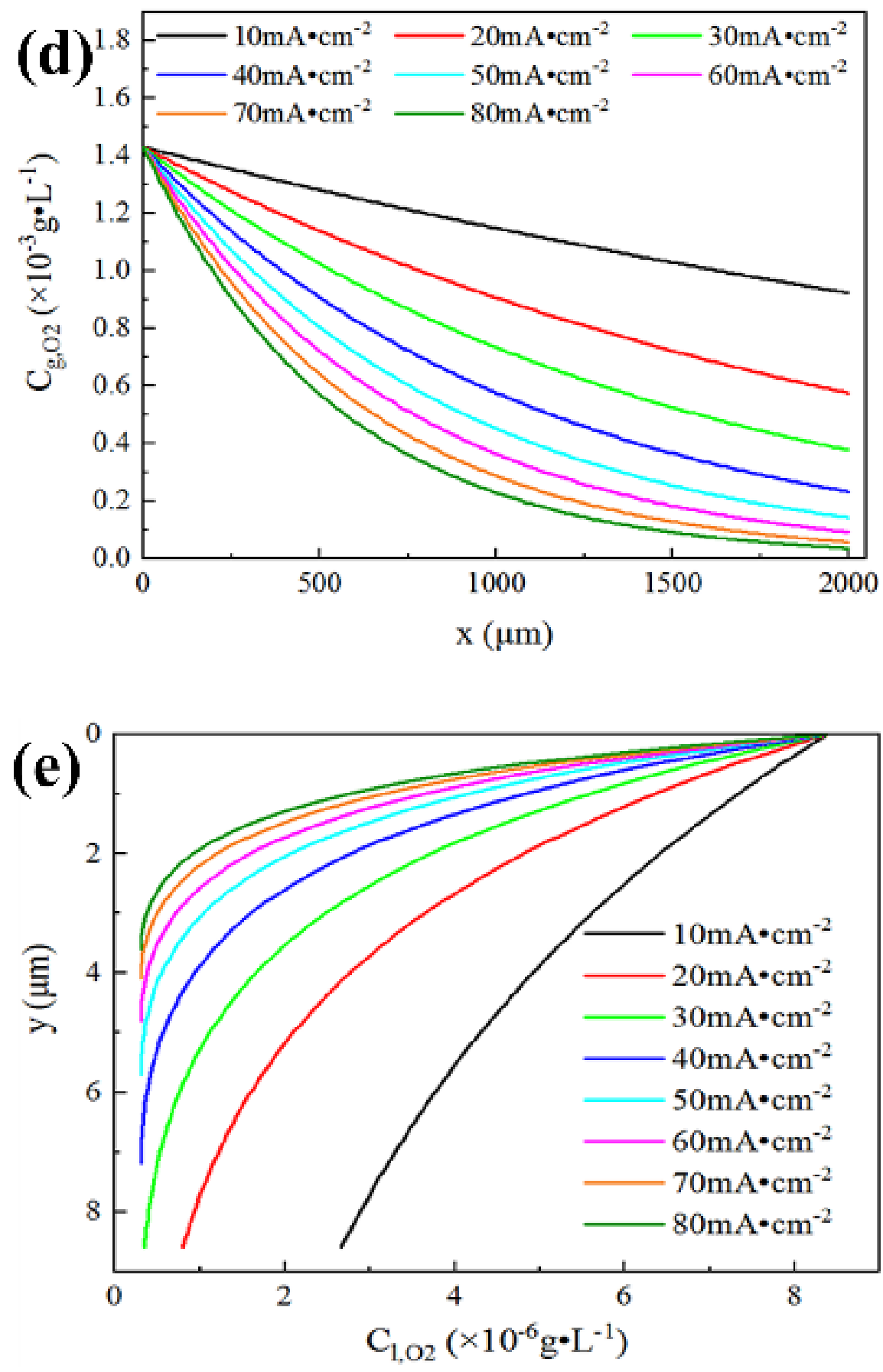

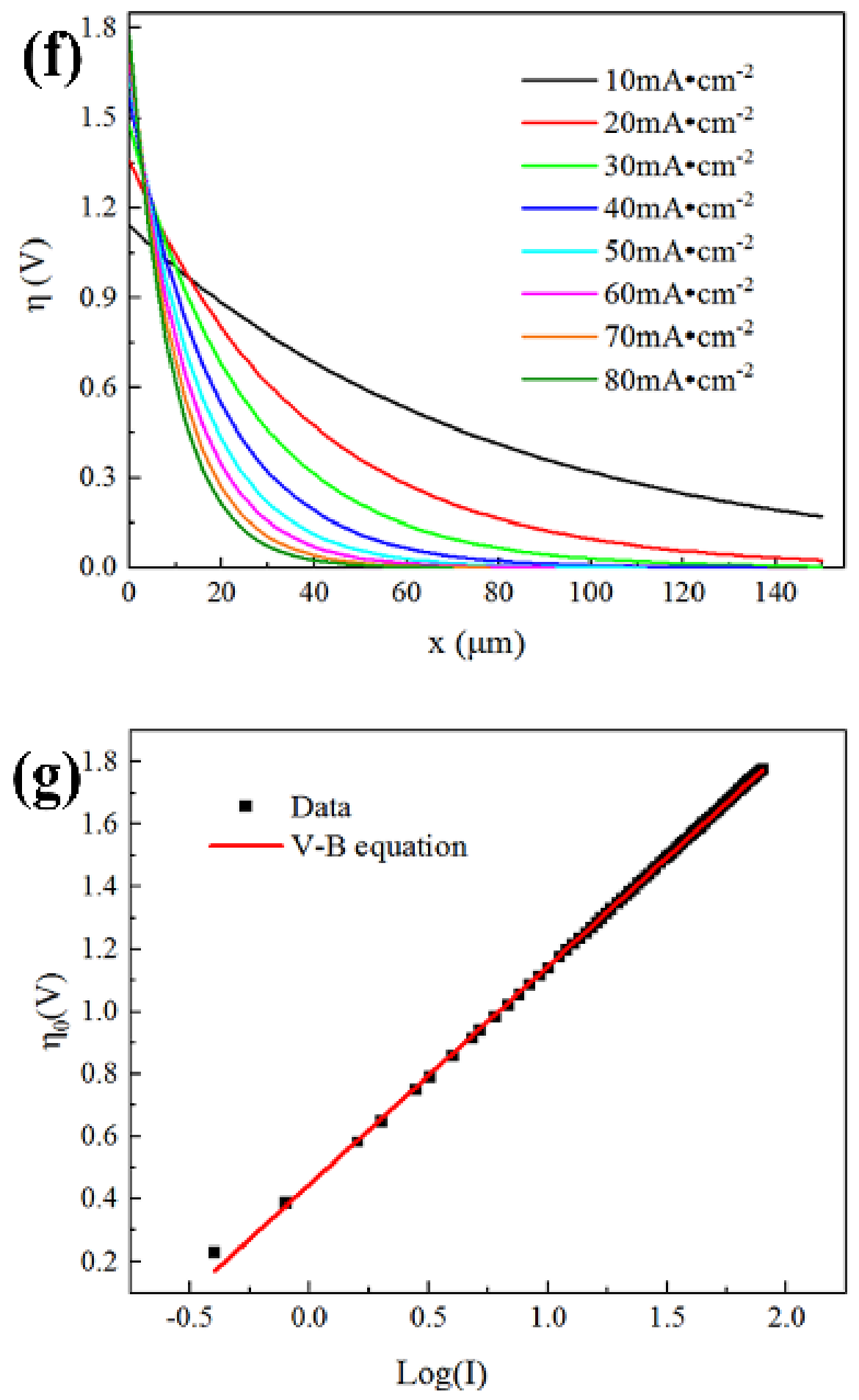

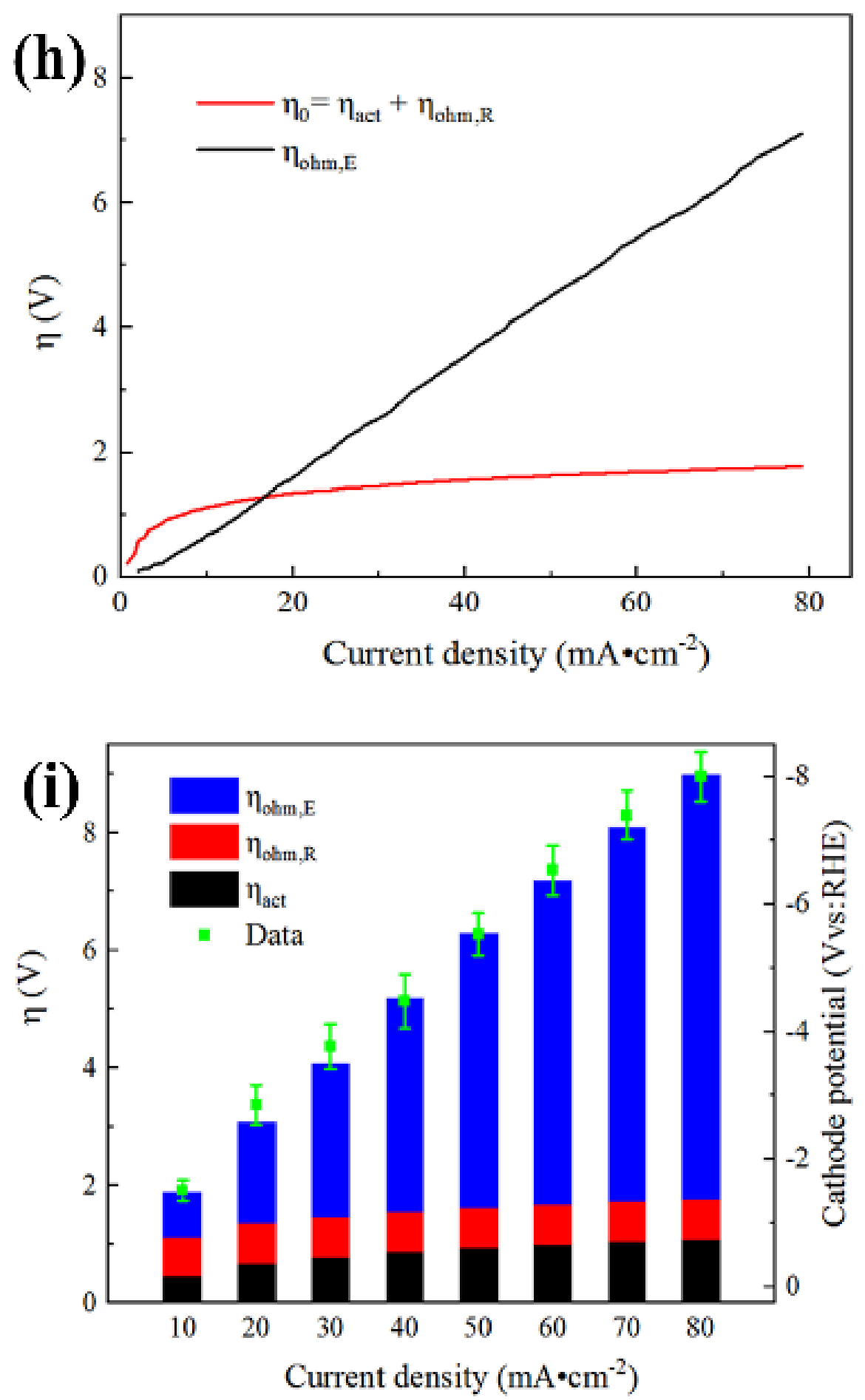

Fig.4 Model and simulation results. Convenient for discussion, current density (I, A) and $\eta(\mathrm{V})$ overpotential are positively, $\eta=0.64-\mathrm{E}$. Where $\mathrm{E}(\mathrm{V})$ is the cathode potential and is generally negative. The thermodynamic equilibrium potential of hydrogen peroxide generated by oxygen reduction under the conditions of $\mathrm{P}_{\mathrm{O} 2}=1 \mathrm{~atm}, \mathrm{pH}=1.0$, and $298.7 \mathrm{~K}$ is $0.64 \mathrm{v}$. Actual electrode reaction layer over potential at $\mathrm{x}=0, \eta_{0}=0.64-\mathrm{E}-\mathrm{IRL} . \mathrm{R}=\mathrm{R}_{\mathrm{GDL}}+\mathrm{R}_{\mathrm{E}} . \mathrm{R}_{\mathrm{E}}$ is the volumetric resistance of the electrolyte 
and diaphragm. $R_{\mathrm{GDL}}$ is the solid-phase volumetric resistance of the diffusion layer of the gas diffusion electrode. $\mathrm{L}$ is the thickness of electrolyte (i.e. the distance between the anode and cathode, cm). In Fig.4, the physical meanings and values of the symbols involved in the equation are shown in Table.2. (a) Schematic diagram of gas diffusion electrode section; (b) Schematic diagram of simplified model of reaction layer of gas diffusion electrode;(c) Section diagram of thin-layer plate electrode model;(d) Simulation results of oxygen concentration attenuation with depth $\mathrm{x}$ in the dry region under different current densities in the $\mathrm{X}$ direction, where: $C_{g}=C_{g 0} \exp \left(\frac{-x}{\mathrm{~L} \mathrm{Dg}}\right), \quad \mathrm{L} \mathrm{Dg}=\left(\frac{\mathrm{nF} \tilde{D}_{g} C_{g 0}}{2 i^{0} S_{1}}\right)^{\frac{-1}{2}} \sinh ^{\frac{-1}{2}}\left(\frac{\eta}{b}\right) ;(\mathbf{e})$ Simulation results of oxygen concentration attenuation with depth $\mathrm{y}$ in wet region under different current density in Y direction, where: $C_{l}=C_{l 0} \frac{\exp \left[\frac{(y-)}{L_{\mathrm{Dl}}}\right]+\exp \left[-\frac{(y-)}{L_{\mathrm{Dl}}}\right]}{\exp \left(\overline{L_{\mathrm{Dl}}}\right)+\exp \left(-\frac{\overline{L_{\mathrm{Dl}}}}{2}\right)}$, taking $\Delta=4 \mathrm{~L}_{\mathrm{dl}}$; (f) Simulation results of attenuation of overpotential with depth $\mathrm{x}$ in the wet region under different current densities in the $\mathrm{X}$ direction, where: $\eta=\eta_{0} \exp \left(-\frac{x}{L_{\Omega}}\right), L_{\Omega}=\left(\frac{b}{2 i^{0} S_{1} \tilde{\rho}_{l}}\right)^{\frac{1}{2}} \ln \left[\frac{\tanh \left(\frac{\eta_{0}}{4 b}\right)}{\tanh \left(\frac{\eta_{0}}{4 b}-\frac{1}{4}\right)}\right], \eta_{0}$ is the electrode reaction layer overpotential at $\mathrm{x}=0 ;(\mathrm{g})$ According to the derived polarization curve equation (2) and the experimental point, the Tafel value and the exchange current density are fitted. $\eta_{0}=a+b^{\prime} \log I$, due to $\eta_{0} / b i, 1$, experimental data points in the region of the strong polarization, the Tafel slope obtained by fitting line value b, and exchange current density $\mathrm{i}^{0}$ obtained by the intercept; (h) The polarization curve is simulated based on the derived equation. Among them: the black line is the simulated ohmic polarization curve of electrolyte and diaphragm under the condition of $3.0 \mathrm{~cm}$ electrolyte thickness, $\eta=\mathrm{IR}_{\mathrm{E}} \mathrm{L}$. Fitting empirical equation $\mathrm{R}_{\mathrm{E}}=656^{*} \exp (-\mathrm{I} / 0.315)+29.1$; the red line is the simulated polarization curve of electrochemical polarization and wet zone liquid resistance when the electrolyte thickness approaches zero, $I=\sqrt{\frac{2 i^{0} S_{1} b}{\tilde{\rho}_{l}}}\left[\exp \left(\frac{\eta_{0}}{2 b}\right)-\exp \left(-\frac{\eta_{0}}{2 b}\right)\right] ;(\mathbf{i})$ histogram of over potential decomposition under different current densities. Among them: black column for electrochemical polarization $\left(\eta_{\text {act }}, \mathrm{V}\right)$, calculated by the equation $(2)$, and red column says ohm polarization caused by wet area liquid resistance $\left(\eta_{\mathrm{ohm}, \mathrm{R}}, \mathrm{V}\right)$, calculated by the equation $\eta_{\mathrm{ohm}, \mathrm{R}}=\eta_{0}-\eta_{\text {act }}$. Blue column says ohm polarization caused by electrolyte and diaphragm $\left(\eta_{\mathrm{ohm}, \mathrm{E}}, \mathrm{V}\right)$, calculated by the equation $\eta_{\mathrm{ohm}, \mathrm{E}}=\mathrm{IR} \mathrm{E}_{\mathrm{E}} \mathrm{L}$. The green point is the experimental point of cathode polarization curve corresponding to different current density. On the right side of the y coordinate for the cathode potential $\mathrm{E}, \mathrm{E}=0.64-\left(\eta_{\mathrm{act}}+\eta_{\mathrm{ohm}, \mathrm{R}}+\eta_{\mathrm{ohm}, \mathrm{E}}\right)$.

Gas and liquid phase mass transfer resistance and solid and liquid phase resistance exist in the gas diffusion electrode used in industrial production, resulting in uneven current density and concentration polarization in the electrode, which makes some reaction surfaces in the reaction layer not fully utilized. However, the test results of trace samples in the electrochemical workstation can't accurately reflect the complex pore structure and pore wall properties of the actual porous carbon electrode. Therefore, it is helpful for engineering amplification to establish a model for the polarization process of the actual gas diffusion electrode and describe the variation law of the actual polarization curves.

The GDE reaction layer represented in Fig.4a is simplified into two structural regions by using the "thin-layer plate model". The simplified model of the electrode reaction layer is shown in Fig.4b. One is the "dry zone", which consists of hydrophobic components and their surrounding pores. The other is the "wet zone", which consists of the electrolyte and the catalyst aggregates soaked in it. These two regions exist in a "thin and long" form and form a continuous network of staggered arrangements. Assuming that the z-axis direction electrode is uniform, the schematic diagram of the partially enlarged dry and wet area of XY section is shown in Fig.4c.The $\mathrm{X}$ axis reaction zone length is equal to $\mathrm{d}(\mu \mathrm{m})$, and $\mathrm{Y}$ direction electrode reaction thickness in the wet area is $2 \Delta(\mu \mathrm{m})$.

For the ideal planar electrode with smooth surface, the reaction layer is very thin. The catalyst aggregates are small, and it is evenly mixed with the binder. This situation is similar to the electrochemical workstation, with only electrochemical polarization, and the relationship between current and potential can be described by Bulter-Volmer equation (2).

$I=2 i^{0} S_{1} \mathrm{~d} \sinh (2)$

However, for the thin-layer electrode model, in addition to the electrochemical polarization caused by the 
reaction in the reaction zone, there may be three kinds of polarization, namely (1) the attenuation of the oxygen concentration in the dry zone in the $\mathrm{x}$ direction, and (2) the concentration polarization of the dissolved oxygen in the y direction caused by the mass transfer resistance in the liquid phase.(3) changes in electromotive force and current density in the $\mathrm{x}$ direction caused by liquid phase resistance. In the following, we will evaluate the importance of each polarization by using the method of characteristic reaction depth $\mathrm{Lx}(\mu \mathrm{m})$, which is the depth at which the concentration of particles (including oxygen molecules, electrons, etc.) drops to $1 / \mathrm{e}$ of the initial value. The characteristics of the electrode reaction depth is not only related to electrode properties (such as catalytic activity of the electrode, specific surface area, pore size distribution, liquid phase resistance, gas solubility, diffusion coefficient, etc.), also affected by the overpotential $\eta_{0}$ of electrode surface. The detailed derivation of the characteristic reaction depth equation is shown in Supporting information, Part 4.

We calculate the characteristic reaction depth Lx under different current densities, as shown in Fig4d, e and f. Considering that industrial applications are generally carried out under strong current and strong polarization conditions, we discuss the characteristic reaction depth $\mathrm{Lx}$ under the condition of $\eta_{0}=1.78 \mathrm{~V}$, $\mathrm{I}=80 \mathrm{~mA}^{*} \mathrm{~cm}^{-2}$.

$L_{\mathrm{Dg}}=546 \mu \mathrm{m}$, this means that in the dry region, it takes $546 \mu \mathrm{m}$ for the gas phase oxygen concentration to decay in the $\mathrm{x}$ direction to $1 / \mathrm{e}(=36.8 \%)$ of the initial value, whereas in the wet region, the $\mathrm{d}$ value is about $50 \mu \mathrm{m}$. Therefore, the polarization caused by gas phase oxygen concentration in the dry region can be neglected.

$L_{\mathrm{Dl}}=0.90 \mu \mathrm{m}$, this means that under strong polarization conditions, when the concentration of dissolved oxygen caused by mass transfer resistance in the liquid phase attenuates to $36.8 \%$ of the initial value, a depth of $0.90 \mu \mathrm{m}$ is required in the y direction in the wet zone. Considering that the distribution range of hierarchical pore aperture in the self-made GDE ranges from $2 \mathrm{~nm}$ to $5 \mu \mathrm{m}$, the pore diameter is mainly concentrated in the range of $20-80 \mathrm{~nm}$, and there are few holes larger than $1 \mu \mathrm{m}$. Therefore, the concentration polarization of dissolved oxygen in most reaction zones can also be neglected. The simulation results also show that although large holes are beneficial to mass transfer, the reactions in the channel larger than $1 \mu \mathrm{m}$ are concentrated on the surface. Oxygen transport in both dry and wet zones is not a speed- control step affecting the reaction rate. The reaction rate can be increased by increasing the electrochemical active surface area.

Shown in such as Fig. 4f, in greater polarization $(\eta / \mathrm{b}>5)$, the actual characteristics reaction depth attenuates quickly. This means that in the $\mathrm{x}$ direction, the greater the overpotential, the shorter the length of the electromotive force caused by the liquid phase resistance attenuation to zero. Therefore, the effective reaction thickness d in the reaction layer will decrease with the increase of potential, and the GDE will eventually degenerate into a plate electrode. This suggests that moderate current density should be considered to improve the effective surface area of the electrode when optimizing the process conditions of hydrogen peroxide preparation.

Based on the theoretical analysis of the above polarization factors, electrochemical polarization and liquid phase resistance polarization are the main components in the electrode. Therefore, the polarization curve equation derived is

$I=\sqrt{\frac{2 i^{0} S_{1} b}{\tilde{\rho}_{l}}}\left[\exp \left(\frac{\eta_{0}}{2 b}\right)-\exp \left(-\frac{\eta_{0}}{2 b}\right)\right](3)$

The detailed derivation of the equation (3) is shown in Supporting information, Part 4. Next, we use the equation to fit the polarization curve measured in the experiment. The fitting results $\mathrm{i}^{0}$ and $\mathrm{b}$ obtained are shown in Fig. 4g. The fitting parameters are listed in Table.2.

Table.2 Equation symbols, physical meanings and values

Retrieval of physical quantity $\quad$ Retrieval of physical quantity

Physical quantity Physical meaning 


\begin{tabular}{|c|c|}
\hline Retrieval of physical quantity & Retrieval of physical quantity \\
\hline$\overline{\mathrm{C}_{\mathrm{g} 0}}$ & Concentration of the gas phase \\
\hline $\mathrm{C}_{10}$ & Saturation concentration of the gas in solution \\
\hline $\mathrm{D}_{\mathrm{g}}$ & Diffusion coefficient in the gas phase \\
\hline $\mathrm{D}_{1}$ & Diffusion coefficient in solution \\
\hline$D_{g \rightarrow l}$ & Diffusion coefficient of a gas into a solution \\
\hline $\mathrm{F}$ & Faraday's constant \\
\hline Test physical quantity & Test physical quantity \\
\hline $\mathrm{R}_{\mathrm{GDL}}$ & Solid area specific resistance of the electrode \\
\hline $\mathrm{S}_{4}$ & Electrochemical active surface area of GDE \\
\hline$\tilde{\rho}_{S}$ & Solid area specific resistance of GDE \\
\hline$\tilde{\rho}_{l}$ & Liquid phase area specific resistance in reaction layer \\
\hline Computational physical quantity & Computational physical quantity \\
\hline$\tilde{D}_{g}$ & Effective diffusion coefficient of gas through GDE \\
\hline$\tilde{D}_{l}$ & Effective diffusion coefficient of liquid particles through GDE \\
\hline$\tilde{D}_{g \rightarrow l}$ & Effective diffusion coefficient of gas to solution \\
\hline$L_{\mathrm{Dg}}^{0}$ & Characteristic reaction depth of gas phase particle under ideal weak polari \\
\hline$L_{\mathrm{Dl}}^{0}$ & Characteristic reaction depth of liquid phase particles under ideal weakly $\mathrm{f}$ \\
\hline$L_{\Omega}^{0}$ & Characteristic reaction depth of liquid phase resistance in the reaction laye \\
\hline $\mathrm{S}_{1}$ & Total active surface area of catalyst per unit volume of reaction layer \\
\hline $\mathrm{S}_{2}$ & Total active surface area of catalyst in wet area per unit volume \\
\hline p & Density of GDE \\
\hline$\varphi$ & Porosity of GDE \\
\hline Fitting physical quantities and other variables & Fitting physical quantities and other variables \\
\hline $\mathrm{b}$ & Tafel slope \\
\hline$i^{0}$ & Exchange current density \\
\hline d & Effective reaction depth of the electrode \\
\hline $\mathrm{L}_{\mathrm{Dg}}$ & Characteristic reaction depth of gas phase particles under large polarizatio \\
\hline $\mathrm{L}_{\mathrm{Dl}}$ & Characteristic reaction depth of liquid particles under large polarization \\
\hline $\mathrm{L}_{\Omega}$ & Characteristic reaction depth of liquid phase in the reaction layer under la \\
\hline $\mathrm{R}_{\mathrm{E}}$ & Volume specific resistance of bulk phase electrolyte \\
\hline$\Delta$ & Half of the thickness of the dry and wet zone in a thin plate model \\
\hline$\eta_{0}$ & Overpotential of the electrode surface \\
\hline$\eta_{\text {act }}$ & Voltage drop due to electrochemical polarization \\
\hline$\eta_{\mathrm{ohm}, \mathrm{R}}$ & Voltage drop caused by ohmic polarization of the liquid phase in the react \\
\hline$\eta_{\mathrm{ohm}, \mathrm{E}}$ & Voltage drop caused by ohmic polarization of electrolyte resistance \\
\hline
\end{tabular}

The fitting results show that, due to the large overpotential on the electrode surface, the electrode reaction is in the strongly polarized region at the current density greater than $1 \mathrm{~mA}^{*} \mathrm{~cm}^{-2}$, indicating that it is of great significance to further improve the catalytic activity and reduce the overpotential generated by hydrogen peroxide to improve the performance of the electrode. In Fig.4h and i, the simulation results show that with the increase of current density, although the overpotential caused by various polarization processes increases, the potential required to maintain the high current of the electrolyte in the device grows fastest. This means that when preparing hydrogen peroxide industrially, it is necessary to design a reasonable electrochemical reaction device, and optimize the process parameters, and minimize the energy loss caused by the ohmic polarization of the electrolyte, which is the main factor affecting the energy efficiency of hydrogen peroxide industrially. 


\section{Conclusion}

(1) The cheap carbon black and graphite mixed with common PTFE and pore-forming agent are used to construct binary phase region and hierarchical pore structure at mesoscopic scale, forming an efficient gas transmission and dispersion network system, which greatly increases the electrochemical surface area of the catalyst. This simple interface engineering strategy can also be used as a reference for other reaction systems requiring gas-solid-liquid three-phase interfaces.

(2) A gas diffusion electrode with reaction layer and diffusion layer is developed. Gas enters from one side and escapes from the other. A triphase-interfacial 2e- ORR system over a carbon + PTFE catalyst enables the reactant $\mathrm{O}_{2}$ to reach the reaction interface directly from the ambient atmosphere, which simultaneously enhances the reaction rate and suppresses the competitive hydrogen evolution. Under the designed $20 \mathrm{ml}$ $\mathrm{H}$-type reaction device and optimized conditions, the generation rate of $\mathrm{H}_{2} \mathrm{O}_{2}$ reaches $2.50 \mathrm{mmol}^{*} \mathrm{~cm}^{-2 *} \mathrm{~h}^{-1}$, and the Faraday efficiency is $79 \%$, and the cumulative $\mathrm{H}_{2} \mathrm{O}_{2}$ concentration reaches $11.8 \mathrm{wt} \%$.

(3) Based on the model of thin plate electrode, the polarization curve equation is derived and established. Simulation finds that the actual device polarization processes involve electrochemical polarization and liquid resistance ohm polarization occurred in the reaction layer, and ohmic polarization of resistance of bulk phase electrolyte. The effective reaction depth of electrode decreases rapidly with the increase of overpotential. Therefore, it is of great significance to pay more attention to the improvement of catalyst activity. The simulation also shows that with the increase of current density, the energy consumed by ohmic polarization of bulk phase electrolyte increases greatly, which is a problem to be paid attention to in engineering. The simulation and theoretical analysis of the performance of the pair of electrodes are also useful for the engineering research and improvement of other gas diffusion electrodes.

Supported by the National Natural Science Foundation of China (Grant No. 21376226).

\section{References}

[1] Wei Zhou, Xiaoxiao Meng, Jihui Gao, Akram N. Alshawabkeh. Hydrogen peroxide generation from $\mathrm{O}_{2}$ electroreduction for environmental remediation: A state-of-the-art review. Chemosphere. 2019; 225: 588-607.

[2] J.M. Campos-Martin, G. Blanco-Brieva, J.L.G. Fierro. Hydrogen Peroxide Synthesis: An Outlook Beyond the Anthraquinone Process. Angew. Chem.2006;45: 6962-6984.

[3] R. Hage, A. Lienke, Applications of Transition-Metal Catalysts to Textile and Wood-Pulp Bleaching. Angew. Chem. Int. Ed. 2006; 37: 206-222. [4] M. Ksibi, Chemical oxidation with hydrogen peroxide for domestic wastewater treatment. Chem. Eng. J. 2006; 119: 161-165.

[5] M.E. Falagas, P.C. Thomaidis, I.K. Kotsantis, K. Sgouros, G. Samonis, D.E.Karageorgopoulos, Airborne hydrogen peroxide for disinfection of the hospital environment and infection control: a systematic review. Hosp. Infect. 2011; 78: 171-177.

[6] Yongcuan Guan, Weihua Li,Jinli Zhang. Advances in green synthesis of hydrogen peroxide. Chemical progress. 2012; 31: 1641-1647.

[7] Zhimin Qiang, Jih-Hsing Chang, Chin-Pao Huang. Electrochemical generation of hydrogen peroxide from dissolved oxygen in acidic solutions. Water Res. 2002; 36: 85-94.

[8] Yang, S., Verdaguer-Casadevall, A., Arnarson, L., Silvioli, L., Čolić, V., Frydendal, R., Rossmeisl, J., Chorkendorff, I., Stephens, I.E.L. Toward the decentralized electrochemical production of $\mathrm{H}_{2} \mathrm{O}_{2}$ : Afocus on the catalysis. ACS Catal.2018; 8: 4064-4081. 
[9] Ciriminna, R., Albanese, L., Meneguzzo, F., Pagliaro, M. Hydrogen peroxide: A key chemical for today's sustainable development. ChemSusChem. 2016; 9: 3374-3381.

[10] Siahrostami, S., Verdaguer-Casadevall, A., Karamad, M., Deiana,D., Malacrida, P., Wickman, B., Escudero-Escribano, M., Paoli, E. A., Frydendal, R., Hansen, T. W., Chorkendorff, I., Stephens, I. E., Rossmeisl, J. Enabling direct $\mathrm{H}_{2} \mathrm{O}_{2}$ production through rational electrocatalyst design. Nat. Mater. 2013; 12: $1137-1143$.

[11] Shucheng Chen, Zhihua Chen, Samira Siahrostami, Drew Higgins, Dennis Nordlund, Dimosthenis Sokaras, Taeho Roy Kim, Yunzhi Liu, Xuzhou Yan, Elisabeth Nilsson, Robert Sinclair, Jens K. Nørskov, Thomas F. Jaramillo, Zhenan Bao. Designing Boron Nitride Islands in Carbon Materials for Efficient Electrochemical Synthesis of Hydrogen Peroxide. Am. Chem. Soc. 2018; 140: 7851-7859.

[12] Xinjian Shi, Samira Siahrostami, Guo-Ling Li, Yirui Zhang, Pongkarn Chakthranont, Felix Studt, Thomas F Jaramillo, Xiaolin Zheng, Jens K Norskov. Understanding activity trends in electrochemical water oxidation to form hydrogen peroxide. Nat. Commun. 2017; 8: 701-706.

[13] Weifeng Tu, Xinli Li , Renquan Wang, Haripal Singh Malhi, Jingyu Ran, Yanling Shi, Yi-Fan Han. Catalytic consequences of the identity of surface reactive intermediates during direct hydrogen peroxide formation on Pd particles. Journal of Catalysis. 2019; 377: 494-506.

[14] Pengfei Tian, Doudou Ding, Yang Sun, Fuzhen Xuan, Xingyan Xu, Jing Xu, Yi-Fan Han. Theoretical study of size effects on the direct synthesis of hydrogen peroxide over palladium catalysts. Journal of Catalysis. 2019; 369: 95-104.

[15] Yi Wang, Mi Yi, Kun Wang, Shuqin Song. Enhanced electrocatalytic activity for $\mathrm{H}_{2} \mathrm{O}_{2}$ production by the oxygen reduction reaction: Rational control of the structure and composition of multi-walled carbon nanotubes. Chinese Journal of Catalysis. 2019; $40: 523-533$.

[16] Dr. Jennifer K. Edwards; James Pritchard; Li Lu; Marco Piccinini; Greg Shaw; Dr. Albert F. Carley; David J. Morgan; Prof. Christopher J. Kiely; Prof. Graham J. Hutchings. The direct synthesis of hydrogen peroxide using platinum-promoted gold-palladium catalysts. Angew. Chem., Int. Ed. 2014; 53: 2381-2384.

[17] Shibata, S.; Suenobu, T.; Fukuzumi, S. Direct synthesis of hydrogen peroxide from hydrogen and oxygen by using a watersoluble iridium complex and flavin mononucleotide. Angew. Chem.,Int. Ed. 2013; 52: $12327-12331$.

[18] Samanta, C. Direct synthesis of hydrogen peroxide from hydrogen and oxygen: An overview of recent developments in the process. Appl. Catal. A. 2008; 350: 133-149.

[19] Park, J.; Nabae, Y.; Hayakawa, T.; Kakimoto, M.-a. Highly Selective Two-Electron Oxygen Reduction Catalyzed by Mesoporous Nitrogen-Doped Carbon. ACS Catal. 2014; 4: 3749-3754.

[20] Anam Asghar, Abdul Aziz Abdul Raman, Wan Mohd Ashri Wan Daud, Anantharaj Ramalingam. Reactivity, Stability, and Thermodynamic Feasibility of $\mathrm{H}_{2} \mathrm{O}_{2} / \mathrm{H}_{2} \mathrm{O}$ at Graphite Cathode: Application of

Quantum Chemical Calculations in MFCs. American Institute of Chemical Engineers Environ Prog. 2017; 00: $1-14$.

[21] William P. Mounfield, Aaron Garg, Yang Shao-Horn, Yuriy Roman-Leshkov. Electrochemical Oxygen Reduction for the Production of Hydrogen Peroxide. Chem. 2018; 4: 18-19.

[22] Fellinger, Tim-Patrick; Hasche, Frederic; Strasser, Peter; Antonietti, Markus. Mesoporous nitrogendoped carbon for the electrocatalytic synthesis of hydrogen peroxide. Am. Chem. Soc. 2012; 134: 40724075 .

[23] Yanming Liu; Prof. Xie Quan; Xinfei Fan; Dr. Hua Wang; Dr. Shuo Chen. High-yield electrosynthesis of hydrogen peroxide from oxygen reduction by hierarchically porous carbon. Angew. Chem., Int. Ed. 2015; 54: $6837-6841$. 
[24] Yanyan Sun, Shuang Li, Zarko Petar Jovanov, Denis Bernsmeier, Huan Wang, Benjamin Paul, Xingli Wang, Stefanie Kuhl, Peter Strasser. Structure, activity, and faradaic efficiency of nitrogen-doped porous carbon catalysts for direct electrochemical hydrogen peroxide production. ChemSusChem. 2018; 11: 33883395 .

[25] Minjie Wang, Tao Zhao, Wei Luo, Zhanxin Mao, Siguo Chen, Wei Ding, Yonghui Deng, Wei Li, Jing Li, Zidong Wei. Quantified Mass Transfer and Superior Antiflooding Performance of Ordered Macro-Mesoporous Electrocatalysts. AIChE J. 2018; 64: 2881-2889.

[26] Perazzolo, V., Durante, C., Pilot, R., Paduano, A., Zheng, J., Rizzi, G.A., Martucci, A., Granozzi, G., Gennaro, A. Nitrogen and sulfur doped mesoporous carbon as metal-free electrocatalysts for the in situ production of hydrogen peroxide. Carbon. 2015; 95: 949-963.

[27] Tingting Jiang, Yi Wang, Kun Wang, Yeru Liang, Dingcai Wu, Panagiotis Tsiakaras, Shuqin Song. A novel sulfur-nitrogen dual doped ordered mesoporous carbon electrocatalyst for efficient oxygen reduction reaction. Appl. Catal. B-Environ.2016; 189: 1-11.

[28] Lobyntseva, E.; Kallio, T.; Alexeyeva, N.; Tammeveski, K.; Kontturi, K. Electrochemical synthesis of hydrogen peroxide: Rotating disk electrode and fuel cell studies. Electrochim. Acta. 2007; 52: 7262-7269.

[29] Tammeveski, K.; Kontturi, K.; Nichols, R. J.; Potter, R. J.;Schiffrin, D. J. Surface redox catalysis for $\mathrm{O}_{2}$ reduction on quinonemodified glassy carbon electrodes. Electroanal. Chem. 2001; 515: 101-112.

[30] Rensheng Zhong, Yuanhang Qin, Dongfang Niu, Jingwei Tian, Xinsheng Zhang, Xingui Zhou, Shigang Sun, Weikang Yuan. Effect of carbon nanofiber surface functional groups on oxygen reduction in alkaline solution. J. Power Sources. 2013; 225: 192-199.

[31] Hasche, F., Oezaslan, M., Strasser, P., Fellinger, T.P. Electrocatalytic hydrogen peroxide formation on mesoporous non-metal nitrogen-doped carbon catalyst. J. Energy Chem. 2016; 25: 251-257.

[32] Yanyan Sun, Ilya Sinev, Wen Ju, Arno Bergmann, Soren Dresp, Stefanie Kuhl, Camillo Spori, Henrike Schmies, Huan Wang, Denis Bernsmeier, Benjamin Paul, Roman Schmack, Ralph Kraehnert, Beatriz Roldan Cuenya, Peter Strasser. Efficient electrochemical hydrogen peroxide production from molecular oxygen on nitrogen-doped mesoporous carbon catalysts. ACS Catal. 2018; 8: 2844-2856.

[33] Kun Zhao, Xie Quan, Shuo Chen, Hongtao Yu, Yaobin Zhang, Huimin Zhao. Enhanced electro-Fenton performance by fluorine-doped porous carbon for removal of organic pollutants in wastewater. Chem. Eng. J. 2018; 354: 606-615.

[34] Kun Zhao, Yan Su, Xie Quan, Yanming Liu, Shuo Chen, Hongtao Yu. Enhanced $\mathrm{H}_{2} \mathrm{O}_{2}$ production by selective electrochemical reduction of $\mathrm{O}_{2}$ on fluorine-doped hierarchically porous carbon. Catal. 2018; 357: $118-126$.

[35] Kunquan Li, Jiamin Liu, Jun Li, Zeqing Wan. Effects of $\mathrm{N}$ mono- and N/P dual-doping on $\mathrm{H}_{2} \mathrm{O}_{2}, \mathrm{OH}$ generation, and $\mathrm{MB}$ electrochemical degradation efficiency of activated carbon fiber electrodes. Chemosphere. 2018; 193: 800-810.

[36] Sarapuu, A.; Vaik, K.; Schiffrin, D. J.; Tammeveski, K. Electrochemical reduction of oxygen on anthraquinone-modified glassy carbon electrodes in alkaline solution. Electroanal. Chem. 2003; 541: 23-29.

[37] Vaik, K.; Sarapuu, A.; Tammeveski, K.; Mirkhalaf, F.; Schiffrin, D. J. Oxygen reduction on phenanthrenequinonemodified glassy carbon electrodes in 0.1 M KOH. Electroanal. Chem. 2004; 564: 159-166.

[38] Strasser, P.; Gliech, M.; Kuehl, S.; Moeller, T. Electrochemical processes on solid shaped nanoparticles with defined facets. Chem.Soc. Rev. 2018; 47: 715-735.

[39] Beermann, V.; Gocyla, M.; Kuhl, S.; Padgett, E.; Schmies, H.;Goerlin, M.; Erini, N.; Shviro, M.; Heggen, M.; Dunin-Borkowski, R.E.; Muller, D. A.; Strasser, P. Tuning the Electrocatalytic Oxygen Reduction 
Reaction Activity and Stability of Shape-Controlled Pt-Ni Nanoparticles by Thermal Annealing - Elucidating the Surface Atomic Structural and Compositional Changes. Am. Chem. Soc. 2017; 139: 16536-16547.

[40] Shucheng Chen, Zhihua Chen, Samira Siahrostami, Taeho Roy Kim, Dennis Nordlund, Dimosthenis Sokaras, Stanislaw Nowak, John W. F. To, Drew Higgins, Robert Sinclair, Jens K. Norskov, Thomas F. Jaramillo, Zhenan Bao. Defective Carbon-Based Materials for the Electrochemical Synthesis of Hydrogen Peroxide. ACS Sustainable Chem. Eng. 2018; 6: 311-317.

[41] Shuang Li, Chong Cheng, Hai-Wei Liang, Xinliang Feng, Arne Thomas. 2D Porous Carbons prepared from Layered Organic-Inorganic Hybrids and their Use as Oxygen-Reduction Electrocatalysts. Adv. Mater. 2017; 29: 700-707.

[42] Yiran Yang, Fei He, Yanfei Shen, Xinghua Chen, Hao Mei, Songqin Liu, Yuanjian Zhang. A biomass derived N/C-catalyst for the electrochemical production of hydrogen peroxide. Chem. Commun. 2017; 53: 9994-9997.

[43] Shuang Li, Chong Cheng, Xiaojia Zhao, Johannes Schmidt, Arne Thomas. Active Salt/Silica-Templated 2D Mesoporous FeCo-Nx-Carbon as Bifunctional Oxygen Electrodes for Zinc-Air Batteries. Angew. Chem. Int. Ed. 2018; 57: 1856-1862.

[44] Iglesias, D.; Giuliani, A.; Melchionna, M.; Marchesan, S.;Criado, A.; Nasi, L.; Bevilacqua, M.; Tavagnacco, C.; Vizza, F.; Prato,M.; Fornasiero, P. N-Doped Graphitized Carbon Nanohorns as a Forefront Electrocatalyst in Highly Selective $\mathrm{O}_{2}$ Reduction to $\mathrm{H}_{2} \mathrm{O}_{2}$. Chem. 2018; 4: 106-123.

[45] Kruusenberg, I.; Leis, J.; Arulepp, M.; Tammeveski, K. Oxygen Reduction on Carbon Nanomaterial Modified Glassy Carbon Electrodes in Alkaline Solution. Solid State Electrochem. 2010; 14: 1269-1277.

[46] Lei Han, Yanyan Sun, Shuang Li, Chong Cheng, Christian E. Halbig, Patrick Feicht, Jessica Liane Hubner, Peter Strasser, Siegfried Eigler. In-Plane Carbon Lattice-Defect Regulating Electrochemical Oxygen Reduction to Hydrogen Peroxide Production over Nitrogen-Doped Graphene. ACS Catal. 2019; 9: 12831288 .

[47] Haijian Luo, Chaolin Li, Chiqing Wu, Wei Zheng, Xiaoqing Dong. Electrochemical degradation of phenol by in situ electro-generated and electro-activated hydrogen peroxide using an improved gas diffusion cathode. Electrochim. Acta. 2015; 186: 486-493.

[48] Jun Li, Guangxu Chen, Yangying Zhu, Zheng Liang, Allen Pei, Chun-Lan Wu, Hongxia Wang, Hye Ryoung Lee, Kai Liu, Steven Chu, Yi Cui. Efficient electrocatalytic $\mathrm{CO}_{2}$ reduction on a three-phase interface. Nature Catalysis. 2018; 1: 592-600.

[49] Shiming Chen, Siglinda Perathoner, Claudio Ampelli, Chalachew Mebrahtu, Dangsheng Su, Gabriele Centi. Room-temperature electrocatalytic synthesis of $\mathrm{NH}_{3}$ from $\mathrm{H}_{2} \mathrm{O}$ and $\mathrm{N}_{2}$ in a gas-liquid-solid threephase reactor. ACS Sustain. Chem. Eng. 2017; 5: 7393-7400.

[50] Zarei, M., Salari, D., Niaei, A., Khataee, A. Peroxi-coagulation degradation of C.I. Basic Yellow 2 based on carbon-PTFE and carbon nanotube-PTFE electrodes as cathode. Electrochim. Acta .2009; 54: 6651-6660.

[51] Khataee, A.R., Safarpour, M., Zarei, M., Aber, S. Electrochemical generation of $\mathrm{H}_{2} \mathrm{O}_{2}$ using immobilized carbon nanotubes on graphite electrode fed with air: Investigation of operational parameters. Electroanal. Chem. 2011; 659: 63-68.

[52] Babaei-Sati, R., Basiri Parsa, J. Electrogeneration of $\mathrm{H}_{2} \mathrm{O}_{2}$ using graphite cathode modified withelectrochemically synthesized polypyrrole/MWCNT nanocomposite for electro-Fenton process. Ind. Eng.Chem. 2017; 52: 270-276.

[53] Flores, N., Thiam, A., Rodríguez, R.M., Centellas, F., Cabot, P.L., Garrido, J.A., Brillas, E., Sirés, I. Electrochemical destruction of trans-cinnamic acid by advanced oxidation processes: kinetics, mineralization, 
and degradation route. Environ. Sci. Pollut. Res. 2017; 24: 6071-6082.

[54] Darvishi, R., Soltani, C., Rezaee, A., Khataee, A. Combination of carbon black- ZnO/UV process with an electrochemical process equipped with a carbon black -PTFE-coated gas-diffusion cathode for removal of a textile dye. Ind. Eng. Chem. Res. 2013; 52: 14133-14142.

[55] Soltani, R.D.C., Rezaee, A., Khataee, A.R., Godini, H. Electrochemical generation of hydrogen peroxide using carbon black-, carbon nanotube-, and carbon black/ carbon nanotube-coated gas-diffusion cathodes: effect of operational parameters and decolorization study. Res Chem Intermed. 2013; 39: 4277-4286.

[56] Fangke Yu, Minghua Zhou, Xinmin Yu. Cost-effective electro-Fenton using modified graphite felt that dramatically enhanced on $\mathrm{H}_{2} \mathrm{O}_{2}$ electro-generation without external aeration. Electrochim. Acta. 2015; 163: 182-189.

[57] Yiping Sheng, Shili Song, Xiuli Wang, Laizhou Song, Chunjia Wang, Honghong Sun, Xueqing Niu. Electrogeneration of hydrogen peroxide on a novel highly effective acetylene black-PTFE cathode with PTFE film. Electrochim. Acta. 2011; 56: 8651-8656.

[58] Yiping Sheng, Yue Zhao, Xiuli Wang, Rui Wang, Ting Tang. Electrogeneration of $\mathrm{H}_{2} \mathrm{O}_{2}$ on a composite acetylene black-PTFE cathode consisting of a sheet active core and a dampproof coating. Electrochim. Acta.2014; 133: 414-421.

[59] Thi Xuan Huong Le, Mikhael Bechelany, Joffrey Champavert, Marc Cretin. A highly active based graphene cathode for the electro-Fenton reaction. RSC Adv. 2015; 5: 42536-42539.

[60] Thi Xuan Huong Le, Mikhael Bechelany, Stella Lacour, Nihal Oturan, Mehmet A. Oturan, Marc Cretin. High removal efficiency of dye pollutants by electron-Fenton process using a graphene based cathode. Carbon. 2015; 94: 1003-1011.

[61] Weilu Yang, Minghua Zhou, Jingju Cai, Liang Liang, Gengbo Ren, Lili Jiang. Ultrahigh yield of hydrogen peroxide on graphite felt cathode modified with electrochemically exfoliated graphene. Mater. Chem. A. 2017; 5: 8070-8080.

[62] Divyapriya, G., Thangadurai, P., Nambi, I. Green Approach To Produce a Graphene thin film on a conductive LCD matrix for the oxidative transformation of ciprofloxacin. ACS Sustainable Chem. Eng. 2018; 6: 3453-3462.

[63] Hyo Won Kim, Michael B. Ross, Nikolay Kornienko, Liang Zhang, Jinghua Guo, Peidong Yang, Bryan D. McCloskey. Efficient hydrogen peroxide generation using reduced graphene oxide-based oxygen reduction electrocatalysts. Nature Catalysis. 2018; 1: 282-290

[64] Lei Zhou, Minghua Zhou, Chao Zhang, Yonghai Jiang, Zhaoheng Bi, Jie Yang. Electro-Fenton degradation of p-nitrophenol using the anodized graphite felts. Chem. Eng. J. 2013; 233: 185-192.

[65] Jie Miao, Hui Zhu, Yang Tang, Yongmei Chen, Pingyu Wan. Graphite felt electrochemically modified in $\mathrm{H}_{2} \mathrm{SO}_{4}$ solution used as a cathode to produce $\mathrm{H}_{2} \mathrm{O}_{2}$ for pre-oxidation of drinking water. Chem. Eng. J. 2014; 250: $312-318$.

[66] Zhiyi Lu, Guangxu Chen, Samira Siahrostami, Zhihua Chen, Kai Liu, Jin Xie, Lei Liao, Tong Wu, Dingchang Lin, Yayuan Liu, Thomas F. Jaramillo, Jens K. Norskov, Yi Cui. High-efficiency oxygen reduction to hydrogen peroxide catalysed by oxidized carbon materials. Nature Catalysis. 2018; 1: 156-162.

[67] Fellinger, T.P., Hasche, F., Strasser, P., Antonietti, M. Mesoporous nitrogen-doped carbon for the electrocatalytic synthesis of hydrogen peroxide. Journal of the American Chemical Society. 2012; 134: 4072-4075.

[68] Yinghui Lee, Feng Li, Kuohsin Chang, Chichang Hu, Takeo Ohsaka. Novel synthesis of N-doped porous carbons from collagen for electrocatalytic production of $\mathrm{H}_{2} \mathrm{O}_{2}$. Appl. Catal. B-Environ. 2012; 126: $208-214$. 
[69] Roldan, L., Truong-Phuoc, L., Anson-Casaos, A., Pham-Huu, C., Garcia-Bordeje, E. Mesoporous carbon doped with N,S heteroatoms prepared by one-pot auto-assembly of molecular precursor for electrocatalytic hydrogen peroxide synthesis. Catal. Today. 2018; 301: 2-10.

[70] Arman Bonakdarpour, Daniel Esau, Hillary Cheng, Andrew Wang, Elod Gyenge, David P. Wilkinson. Preparation and electrochemical studies of metal-carbon composite catalysts for small-scale electrosynthesis of $\mathrm{H}_{2} \mathrm{O}_{2}$. Electrochim. Acta. 2011; 56: 9074-9081

[71] Jussara F. Carneiro, Maria J. Paulo, Mohamed Siaj, Ana C. Tavares, Marcos R.V. Lanza. $\mathrm{Nb}_{2} \mathrm{O}_{5}$ nanoparticles supported on reduced graphene oxide sheets as electrocatalyst for the $\mathrm{H}_{2} \mathrm{O}_{2}$ electrogeneration. Catal. 2015; 332: $51-61$.

[72] Chuan Xia, Seoin Back, Stefan Ringe, Kun Jiang, Fanhong Chen, Xiaoming Sun,Samira Siahrostami , Karen Chan, Haotian Wang. Confined local oxygen gas promotes electrochemical water oxidation to hydrogen peroxide. Nature Catalysis. 2020; 3: 125-134.

[73] Qian Zhao, Jingkun An, Shu Wang, Yujie Qiao, Chengmei Liao, Cong Wang, Xin Wang, Nan Li. Superhydrophobic Air-Breathing Cathode for Efficient Hydrogen Peroxide Generation through Two-Electron Pathway Oxygen Reduction Reaction. ACS Appl. Mater. Interfaces. 2019; 11: 35410-35419. 